\title{
Sex-specific Esr2 mRNA expression in the rat hypothalamus and amygdala is altered by neonatal bisphenol A exposure
}

\author{
Jinyan Cao ${ }^{1}$, Linwood Joyner ${ }^{1}$, Jillian A Mickens ${ }^{1}$, Stephanie M Leyrer ${ }^{1}$ and Heather B Patisaul ${ }^{1,2}$ \\ ${ }^{1}$ Department of Biology and ${ }^{2}$ Keck Center for Behavioral Biology, North Carolina State University, Raleigh, \\ North Carolina 27695, USA
}

Correspondence should be addressed to H B Patisaul at Department of Biology, North Carolina State University; Email: Heather_Patisaul@ncsu.edu

\begin{abstract}
Perinatal life is a critical window for sexually dimorphic brain organization, and profoundly influenced by steroid hormones. Exposure to endocrine-disrupting compounds may disrupt this process, resulting in compromised reproductive physiology and behavior. To test the hypothesis that neonatal bisphenol A (BPA) exposure can alter sex-specific postnatal Esr2 (Er $\beta$ ) expression in brain regions fundamental to sociosexual behavior, we mapped Esr2 mRNA levels in the principal nucleus of the bed nucleus of the stria terminalis (BNSTp), paraventricular nucleus (PVN), anterior portion of the medial amygdaloid nucleus (MeA), super optic nucleus, suprachiasmatic nucleus, and lateral habenula across postnatal days (PNDs) 0-19. Next, rat pups of both sexes were subcutaneously injected with $10 \mu \mathrm{g}$ estradiol benzoate (EB), $50 \mu \mathrm{g} / \mathrm{kg}$ BPA (LBPA), or $50 \mathrm{mg} / \mathrm{kg}$ BPA (HBPA) over the first 3 days of life and Esr2 levels were quantified in each region of interest (ROI) on PNDs 4 and 10. EB exposure decreased Esr2 signal in most female ROIs and in the male PVN. In the BNSTp, Esr2 expression decreased in LBPA males and HBPA females on PND 10, thereby reversing the sex difference in expression. In the PVN, Esr2 mRNA levels were elevated in LBPA females, also resulting in a reversal of sexually dimorphic expression. In the MeA, BPA decreased Esr2 expression on PND 4. Collectively, these data demonstrate that region- and sex-specific Esr2 expression is vulnerable to neonatal BPA exposure in regions of the developing brain critical to sociosexual behavior in rat.

Reproduction (2014) 147 537-554
\end{abstract}

\section{Introduction}

Sexually dimorphic brain organization, a process essential for establishing later in life - sex differences in neuroendocrine physiology and behavior, is profoundly influenced by endogenous steroid hormones during perinatal development. In rodents, brain masculinization is primarily induced by estrogens locally derived from circulating gonadal androgen

\footnotetext{
This paper forms part of a special issue of Reproduction on Endocrine Disrupters. This article was presented at the 7th Copenhagen Workshop on Endocrine Disrupters, 28-31 May 2013. The meeting was supported by the Danish Ministry of the Environment - Environmental Protection Agency as an activity under the Danish Centre on Endocrine Disrupters. Publication of this special issue has been supported by the Society for Reproduction and Fertility. The opinions or views expressed in this special issue are those of the authors, and do not necessarily reflect the opinions or recommendations of the Danish Ministry of the Environment - Environmental Protection Agency or the Society for Reproduction and Fertility. The Guest Editors for this special issue were Anna-Maria Andersson, Hanne Frederiksen, Niels Erik Skakkebæk, Rigshospitalet, Denmark, Kenneth M Grigor, Western General Hospital, Edinburgh, UK and Jorma Toppari, University of Turku, Finland.
}

(Simerly 2002, McCarthy 2008, McCarthy et al. 2009). The absence of estrogens generally permits the ontogeny of female-typical brain development. Estrogen action is predominantly mediated by the two nuclear estrogen receptor (ER) subtypes: ESR1 (ER $\alpha)$ (Greene et al. 1986) and ESR2 (ERß) (Kuiper et al. 1996). Administration of estrogens or aromatizable androgens to females, blockade of ERs in males, or exposure to endocrine-disrupting compounds (EDCs) during neonatal life disrupt the sexual differentiation process, resulting in compromised neuroendocrine pathways critical for mediating steroid negative feedback, gonadotropin release, energy homeostasis, and sociosexual behavior (Arai \& Gorski 1968, Simerly 2002, Amateau et al. 2004, Gore 2008, Bader et al. 2011, Faulds et al. 2012, Patisaul et al. 2012). Although the relative role each ESR plays in the estrogendependent organization of sexually dimorphic neuroendocrine pathways remains unclear (Rissman 2008, Wilson \& Westberry 2009, Fan et al. 2010, Handa et al. 2012), in the adult brain ESR2 is thought to play a critical role in the mediation of estrogen-sensitive aspects of mood and social behaviors including 
aggression, anxiety, and sexual behavior (Handa et al. 2012). We have previously shown that Esr1 and Esr2 are dynamically expressed across neonatal development in subregions of the amygdala, as well as several anterior and mediobasal hypothalamic $(\mathrm{MBH})$ nuclei in the rat brain. We have also shown that the sex-specific pattern of ESR expression, particularly Esr2 expression, can be altered by exposure to the plastics component bisphenol A (BPA). In this study, we expand on that prior work and show that neonatal BPA exposure disrupts Esr2 expression in additional regions of the amygdala (AMYG) and hypothalamus important for the coordination of sociosexual behavior and reproductive physiology. Collectively, with our prior work, these studies emphasize that BPA can alter Esr2 expression in regions important for sex-specific behaviors.

BPA was first synthesized as a potential estrogenic compound in the 1930s (Dodds \& Lawson 1936) and entered wide commercial use in the 1950s as a component of many household products such as polycarbonate plastics, epoxy resins, dental sealants, and thermal receipts (Vandenberg et al. 2007, Biedermann et al. 2010). BPA has been found in over $90 \%$ of all humans, with levels higher in children than in adults (Calafat et al. 2008), but the potential health impacts of this widespread, chronic, low level BPA exposure remain controversial. Growing evidence suggests that BPA is associated with adverse outcomes in reproductive (Howdeshell et al. 1999, Vandenberg et al. 2009, Beronius et al. 2010, Cabaton et al. 2011), cardiovascular (Pant et al. 2011), and metabolic (Groff 2010, Newbold 2010) health. In addition, animal and human data suggest that it may change many aspects of affective, cognitive, and reproductive behaviors (Negishi et al. 2004, Porrini et al. 2005, Rubin et al. 2006, Palanza et al. 2008, Cox et al. 2010, Patisaul et al. 2012, Rosenfeld 2012). Concern has been raised that early-life exposure to BPA may alter neural development and ultimately compromise neurobehavior (vom Saal et al. 2007, Chapin et al. 2008, NTP 2008, Palanza et al. 2008, Patisaul \& Polston 2008, Report of Joint FAO/WHO Expert Meeting 2011, Wolstenholme et al. 2011, 2012, Rosenfeld 2012). Notably, in their 2008 evaluation of developmental and reproductive effects of BPA exposure, the National Toxicology Program (NTP) concluded that there was 'some concern for its effects on the brain and behavior' (Shelby 2008). In a 2010 statement, the FDA indicated similar concerns, although it continues to reaffirm its position that 'BPA is safe at the very low levels that occur in some foods' (http://www.fda.gov/newsevents/ publichealthfocus/ucm064437.htm, updated March 2013).

The specific mechanisms by which early-life BPA exposure results in perturbed behavior remain unclear. Compared with estradiol, the binding affinity of BPA is relatively equivalent for Esr1 and Esr2 (Kuiper et al. 1998), but $\sim 10000$ - to 100000 -fold lower (Barkhem et al. 1998, Gould et al. 1998, Andersen et al. 1999, Blair et al. 2000). Thus, although BPA has long been considered to be weakly estrogenic, how it interacts with molecular and cellular targets within the brain to alter estrogen-sensitive neural systems is not clearly established (vom Saal et al. 2007, Wolstenholme et al. 2011). We hypothesize that disruption of ESR expression during the process of brain sexual differentiation may be a mechanism by which BPA induces adverse effects on sex-specific behaviors such as anxiety and sociality.

Understanding how BPA and other EDCs may alter ESR expression during critical windows of brain development requires a detailed map of neonatal ESR distribution in both sexes. We previously reported that the expression of Esr1 and Esr2 mRNA is sexually dimorphic within numerous regions of the neonatal rat brain important for reproductive physiology and behavior (Cao \& Patisaul 2011, 2013), including the preoptic area (POA), $\mathrm{MBH}$ (Cao \& Patisaul 2011), and subregions of the AMYG (Cao \& Patisaul 2013). We found that the degree to which neonatal expression is sexually dimorphic differs regionally and is often transient, with overall levels and the robustness of the sex difference changing with age. These observations support the hypothesis that the two primary isoforms of nuclear ESR may play different functional roles in the sexual differentiation process (Cao \& Patisaul 2011, 2013). Moreover, we showed that neonatal BPA exposure decreased Esr1 and, to an even greater extent, Esr2 in POA (Cao et al. 2012), suggesting that Esr2 is the more sensitive isoform to endocrine disruption. Furthering understanding of how BPA might disrupt Esr2 in the developing hypothalamus is of particular interest because of the purported role Esr2 has in the mediation of sociosexual behaviors.

For this study, we first mapped Esr2 expression in the principal nucleus of the bed nucleus of the stria terminalis (BNSTp), paraventricular nucleus (PVN), anterior part of medial amygdaloid nucleus (MeA), super optic nucleus $(\mathrm{SON})$, suprachiasmatic nucleus (SCN), and lateral habenula (LHb) across postnatal days (PNDs) 0-19. These region of interests (ROIs) were selected for several reasons. First, although there is an abundance of data regarding neural distribution of Esr2 in adult rodents (Shughrue et al. 1997a, 1997b, Laflamme et al. 1998, Osterlund et al. 1998, Shughrue \& Merchenthaler 2001, Mitra et al. 2003, Suzuki \& Handa 2005, Chung et al. 2007), a detailed profile of Esr2 mRNA expression from birth through weaning within these regions is incomplete. Second, most of these ROIs (BNSTp, PVN, MeA, SON, $\mathrm{SCN}$, and $\mathrm{LHb}$ ) express vasopressin (AVP), oxytocin (OT), and/or their receptors (Buijs et al. 1978, Brownstein 1980, De Vries et al. 1984, DeVries et al. 1985, Young \& Gainer 2003, Caldwell et al. 2008). Avp expression of prenatal mouse brain was recently shown to be altered by BPA exposure at a dose considered to be human relevant (Wolstenholme et al. 2012), suggesting that Esr2expressing nuclei within AVP/OT signaling pathways may be vulnerable to endocrine disruption by BPA. In adulthood, the PVN contains Esr2, but not Esr1, and Esr2 is required to initiate estrogen-dependent OT and 
AVP production in both sexes (Nomura et al. 2002, Patisaul et al. 2003). Although it is well established that early-life exposure to sex hormones affects the sexually dimorphic organization of the ROls examined here, including OT and AVP pathways, few studies have specifically examined impacts on early-life Esr2 expression (Perez et al. 2003).

Using tissues from a complementary, previously published study (Cao et al. 2012), the consequences of neonatal BPA exposure on Esr2 expression in the developing brain was assessed in rat pups (both sexes) on PND 4 and PND 10 by administering vehicle, $10 \mu \mathrm{g}$ estradiol benzoate (EB), $50 \mu \mathrm{g} / \mathrm{kg}$ BPA (LBPA), or $50 \mathrm{mg} / \mathrm{kg}$ BPA (HBPA) on PNDs 0-2 (the first 3 days of life) by s.c. injection. Although oral BPA administration is preferable when seeking to model human exposure and assess potential risk (Chapin et al. 2008, Li et al. 2008), because this study was mechanistic in nature and oral dosing to neonates can be stressful and laborious (Cao et al. 2013), s.c. injection was used. Collectively, the results demonstrate that the Esr2 mRNA levels across the postnatal brain are dynamically altered. The data suggest that altered Esr2 expression during the neonatal critical period may underlie reported disruptions of adult reproductive deficiencies and abrogated sex differences in sociosexual behavior across the lifespan. Future studies should explore the possibility that these effects might occur following exposures that better recapitulate human exposure conditions and doses.

\section{Materials and methods}

\section{Animal care, neonatal exposure, and tissue collection}

Tissues were obtained from two prior studies, the details of which are described elsewhere (Cao \& Patisaul 2011, 2013, Cao et al. 2012). For these studies, 20 time pregnant Long-Evans (LE) rats were purchased from Charles River (Raleigh, NC, USA) and individually housed in a temperature, humidity and lightcontrolled room $\left(23{ }^{\circ} \mathrm{C}, 50 \%\right.$ average relative humidity and $14 \mathrm{~h}$ light: $10 \mathrm{~h}$ darkness cycle; lights on at $0700 \mathrm{~h}$ ) at the Biological Resource Facility of North Carolina State University (NCSU), according to the applicable portions of the Animal Welfare Act and the US. Department of Health and Human Services Guide for the Care and use of Laboratory Animals. The procedures were approved by the Institutional Animal Care and Use Committee of NCSU. Both dams and rats were housed in thoroughly washed polysulfone (BPA-free) caging and fed with a semipurified, phytoestrogen-free diet ad libitum (AIN-93G, Test Diet, Richmond, IN, USA) to minimize exposure to exogenous BPA and other EDCs (Brown \& Setchell 2001, Degen et al. 2002, Patisaul 2005, Thigpen et al. 2007, 2013).

\section{Experiment 1: ontogeny of Esr2 expression across male and female postnatal development}

Pups were obtained as described previously (Cao \& Patisaul 2011, 2013). Briefly, female and male pups ( $n=5-7$ per sex, per group) were killed by rapid decapitation on postnatal days 0 (PND $0=$ the day of birth and defined as within $12 \mathrm{~h}$ after littering took place), 2, 4, 7, and 19. The whole head from the PND 0, 2, and 4 animals, and the brains from PND 7 and 19 animals, were rapidly frozen on powdered dry ice and stored at $-80^{\circ} \mathrm{C}$ until cryosectioning. To minimize potential litter effects, no more than two pups of each sex from the same litter were collected at each time point; thus pups of the same sex are from at least three different litters.

\section{Experiment 2: impact of neonatal BPA exposure on postnatal Esr2 expression}

As described previously, pups were obtained from 13 LE dams (Cao et al. 2012) and BPA was injected s.c. daily from PND 0 through PND 2 (a critical period that approximates the latesecond and early-third trimesters of human brain development, Grumbach (2002)). Litter sizes ranged from 9 to 17 pups and were not standardized for size or sex ratio to minimize disruption of maternal care. Males and females $(n=6-9$ per sex per group) were randomly assigned to one of four groups:

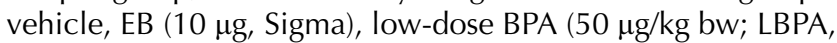
Sigma), or high-dose BPA (50 mg/kg bw; HBPA). All pups within the litter were administered the same compound to prevent cross-contamination ( $3 \mathrm{I}$ each for vehicle, $\mathrm{EB}$, and LBPA, 4 I for HBPA), and each experimental group contained pups from at least $3 \mathrm{I}$ to minimize potential litter effects. All compounds were first dissolved in $100 \%$ ethanol ( $\mathrm{EtOH}$, PharmaCo, Austin, TX, USA), and then sesame oil (Sigma) at a ratio of $10 \% \mathrm{EtOH}$ and $90 \%$ oil (Patisaul et al. 2006). The vehicle was a mixture of $10 \% \mathrm{EtOH}$ and sesame oil. The low dose is the oral reference dose considered 'safe' for human exposure, and the high dose is equivalent to the oral lowest observed adverse effect level (LOAEL; FAO/WHO 2011). Because these experiments were primarily mechanistic in nature, and assessing potential human risk was not a primary goal, injection was used for logistical reasons and to ensure consistent exposure across individual animals. Although injection may result in a higher internal dose than oral exposure (Doerge et al. 2010), at least one study has shown that this difference is not significant in neonatal mice (Taylor et al. 2008). EB was used as a positive control at a dose sufficient to induce complete masculinization of the hypothalamus and to prevent the onset of regular estrous cycles (Aihara \& Hayashi 1989, Nagao et al. 1999). Pups were killed by rapid decapitation on PNDs 4 and 10, and the heads were rapidly frozen on powdered dry ice and stored at $-80^{\circ} \mathrm{C}$ until cryosectioning.

\section{In situ hybridization histochemistry}

Brains were cryosectioned (Leica CM1900, Nussloch, Germany) into three serial sets of coronal sections $(12 \mu \mathrm{m}$ sections for Experiment 1 and $18 \mu \mathrm{m}$ sections for Experiment 2), as described previously (Cao \& Patisaul 2011, 2013, Cao et al. 2012), mounted onto Superfrost plus slides (Fisher Scientific, Pittsburgh, PA, USA), and stored at $-80^{\circ} \mathrm{C}$ until in situ hybridization histochemistry $(\mathrm{ISHH})$ processing. For each experiment, one set of sections containing all the ROIs from every animal (both sexes and all time points) were processed and analyzed 
simultaneously as a large batch to eliminate batch effects. Thus two large batches of ISHH were performed: one for the mapping experiment (Experiment 1) and one for the BPA exposure experiment (Experiment 2). The templates for the antisense probes of Esr2 were 501-bp cDNA fragments and cloned into the PCRII-TOPO vector. Details regarding probe specificity, synthesis and purification, and the ISHH procedure are available elsewhere (Cao \& Patisaul 2011, 2013, Cao et al. 2012). Dried slides were exposed to Kodak Biomax MR X-ray film (Eastman Kodak) for 13 days for Experiment 1 and for 17 days for Experiment 2, along with an autoradiographic ${ }^{14} \mathrm{C}$ microscale (Amersham Life Sciences) to generate the optical density curve. The autoradiographic films were developed using a Konica SRX101A processor (Konica Corporation, Tokyo, Japan). To confirm the results obtained from the autoradiograms, the slides were dipped in NTB3 emulsion (Kodak), kept at $4{ }^{\circ} \mathrm{C}$ for 73 days, and then developed in Dektol developer and Kodak fixant (Kodak) according to the user manual. Then all slides were counterstained with Mayer's hematoxylin (Sigma), as described previously (Cao \& Patisaul 2011, Cao et al. 2012), to visualize cell-specific silver grain clusters.

\section{Landmark identification and image analysis}

The MCID Core Image software program (InterFocus Imaging Ltd, Cambridge, Cambs, UK) was used to quantify Esr2 mRNA signals, as described previously (Cao \& Patisaul 2011, 2013, Cao et al. 2012). ROIs included BNSTp, PVN, MeA, SON, $\mathrm{SCN}$, and LHb. An in-house library of Nissl stained sections was used to identify each ROI across neonatal development (Fig. 1A, B, C and D left panels, encircled with a solid line), and a rat brain atlas (Paxinos \& Watson 2007) was referenced to confirm the location and borders of each ROI (Fig 1A, B, C and $\mathrm{D}$ right panels; ROIs shaded light gray). The area selected (sampling template) for film quantification is encircled in the left panels of Fig. 1 with a dashed line. The size of this quantification area increased across age groups (to account for growth) but was standardized for all animals at that age.

All quantification was conducted by investigators blinded to the exposure groups. For each brain area, ROI and background levels were measured unilaterally from four anatomically matched sections. The resulting values for each brain section after background subtraction were then averaged to obtain a representative measurement (for that $\mathrm{ROI}$ ) for each animal. Optical densities were converted to $\mathrm{nCi} / \mathrm{g}$ tissue equivalents using a 'best fit' curve (5th degree polynomial) generated from the autoradiographic ${ }^{14} \mathrm{C}$ microscales. In all cases, the signal was within the limits of the curve. The measurements for the BNSTp and PVN were completed by two investigators blinded to the exposure groups. There was a high degree of concordance between the two data sets (Pearson's coefficient $>0.98$ ), thus the results were averaged to obtain the final values for those two regions. MeA, SON, and Pe measurements were made by one investigator. Within the $\mathrm{SCN}$, the signal from PND 0 to 19 was so weak, that meaningful quantification was not possible. For other groups/ages in which no data was reported, either no signal was present or there were not enough quality sections per sample available to reach the minimum goal of three samples per group per age per sex.
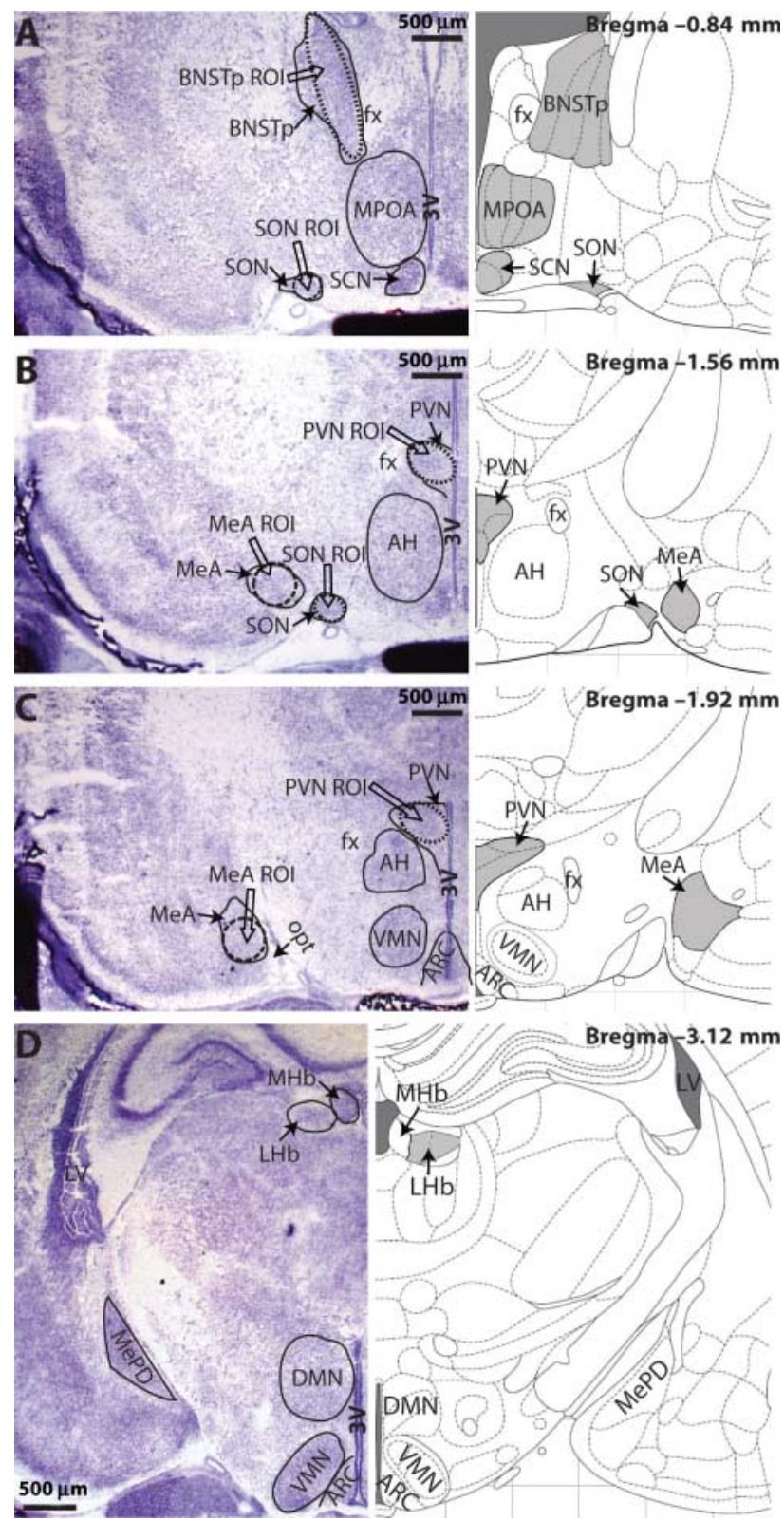

Figure 1 Representative NISSL-stained sections from PND 2 rats depicting each brain region of interest ( $\mathrm{ROI}$, circled with a solid black solid line and indicated by the solid black arrows) and the corresponding sampling template created to define the sampling area (circled with a dashed black line and indicated by the open arrows) for autoradiographic quantification (A, B, C and D, left panel). A sampling template was created for each age according to the size and position of each brain area and then used for all sections, regardless of sex, within that age group.

Representative sections containing a midlevel section of the BNSTp (A), PVN (B and C), SON (A and B), MeA (B and C), and $\mathrm{LHb}(\mathrm{D})$ were obtained from animals in our existing colony and used, along with a standard rat brain atlas (Paxinos \& Watson 2007), to identify the ROI landmarks and anatomical borders for this studies. All depicted sections are matched with their corresponding coronal plates with the ROI shaded in gray; Bregma $-0.84 \mathrm{~mm}$ for the $\mathrm{BNST}$ and $\mathrm{SON},-1.56 \mathrm{~mm}$ for the PVN, SON and MeA, $-1.92 \mathrm{~mm}$ for the PVN and MeA, and $-3.12 \mathrm{~mm}$ for the $\mathrm{LHb}$ (A, B, C, D, right panel). For abbreviations, see list. Scale bar is $500 \mu \mathrm{m}$ in the left panels of A, B, C and D. 


\section{Statistical analysis}

For Experiment 1, all data was first analyzed by two-way ANOVA with sex and age as factors. For Experiment 2, data were analyzed within each age with sex and exposure group as factors. Significant main effects and/or interactions were followed by appropriate one-way ANOVA. And the Dunnett's Multiple Comparison post hoc test was used to compare each age group with PND 0 in Experiment 1, or to compare each exposure group with the vehicle control within in Experiment 2. For Experiment 2, sex differences at each age were identified by $t$-tests. All analyses were two-tailed and results were considered significant when $P \leq 0.05$ within each ROI.

\section{Results}

All results from both experiments are summarized in Tables 1 and 2, including the impact of BPA exposure on sexually dimorphic expression. Because Esr2 signal was observed to be robust in the caudal portion of periventricular hypothalamic nucleus (Pe) on PND 19, it was subsequently quantified and included in the analysis for both experiments. Levels in the SCN were detectable at all ages but too low to be quantified.

\section{Experiment 1: ontogeny of Esr2 expression across male and female postnatal development}

Esr2 mRNA was detected in the Pe, BNSTp, PVN, MeA, $\mathrm{SCN}, \mathrm{SON}$ and LHb (Figs 2, 3 and 4). Consistent with what we have previously observed, Esr2 signal was more robust in the BNSTp and PVN than all other regions examined (Figs 2, 3 and 4). Esr2 mRNA levels were observable but too low to be quantified in the SCN (not shown). Esr2 expression was observed in PND $0 \mathrm{LHb}$ in both sexes, but it decreased with age to the limit of detection, and was thus not quantifiable. For comparison, Esr1 expression was assessed in a companion set of sections labeled previously (Cao \& Patisaul 2013) and no Esr1 signal was observed (Fig. 4E, F). Thus Esr expression in the neonatal LHb appears to be Esr2 only. Quantification across the entire postnatal period was only possible for the BNSTp and PVN (Fig. 2). Because signal was too weak to quantify in younger animals, Esr2 expression was only quantified on PND 19 in the Pe (Fig. 3A) and MeA (Fig. 3B), and on PNDs 7 and 19 in the SON (Fig. 3C).

\section{BNSTp}

Quantification was mainly confined to BNSTp, located in the medial posterior division (Fig. 2A). BNSTp Esr2 signal was expressed in both temporal- and sex-specific patterns (Fig. 2 and Table 1). Two-way ANOVA revealed a significant main effect of age $(F(4,47)=20.93$, $P \leq 0.0001)$, sex $(F(1,47)=9.174, P \leq 0.004)$ as well as a significant interaction $(F(4,49)=5.744, P \leq 0.0008)$. In females $(F(4,24)=21.64, P \leq 0.0001)$, expression was high on PND 0 but rapidly decreased with age and remained low from PNDs 2-19 $(P \leq 0.01)$. In males, there was also a main effect of age $(F(4,23)=10.76$, $P \leq 0.0001)$ with levels peaking on PND 2, then significantly lower on PNDs 4-19. Sexually dimorphic expression of Esr2 was found only on PND 2 (Fig. 2A and $\mathrm{B})$ with higher levels in males $(P \leq 0.05)$.

\section{PVN}

Esr2 mRNA level was robust in the PVN on all days examined (Fig. 2C and D). A main effect of age $(F(4,45)=19.19, P \leq 0.0001)$ was revealed by two-way ANOVA, but no effect of sex. Compared with same sex PND 0 animals, Esr2 signal was significantly increased on PND 7 in males $(P \leq 0.05)$, and in both sexes $(P \leq 0.01)$ on PND 19 (Fig. 2C and D). Expression levels were compared between sexes at each age, but only found to be sexually dimorphic on PND 7, with higher levels in males (Fig. 2C and D and Table 1).

\section{$P e, M e A$, and SON}

We previously observed robust Esr2 expression in the rostral portion of the Pe on PND 19 (Cao \& Patisaul 2011). Similarly, in this study, Esr2 expression was observed to be present in the caudal portion of the PND 19 Pe (Fig. 3A), and was therefore quantified. Expression was sexually dimorphic $(P \leq 0.001)$ with levels higher in PND 19 females than in males. Esr2 expression was also detected in the MeA (Fig. 3B) but quantifiable only on PND 19 and not found to be sexually dimorphic. In the SON, signal was visible as early as on PND 0 (Fig. 3C) but quantifiable only on PNDs 7 and 19. Levels were higher on PND 19 compared with PND 7 and only a trend for sexually dimorphic expression $(P=0.07)$ was found, with higher levels in females (Fig. 3C). Qualitative assessment of silver grain deposition on the emulsion-dipped slides confirmed that the sex difference was appreciable but not large.

Table 1 Esr2 mRNA expression in postnatal rat brain without neonatal BPA exposure.

\begin{tabular}{lccccc}
\hline & PND 0 & PND 2 & PND 4 & PND 7 & PND 19 \\
\hline BNSTp & $F=M$ & $F<M$ & $F=M$ & $F=M$ & $F=M$ \\
PVN & $F=M$ & $F=M$ & $F=M$ & $F<M$ & $F=M$ \\
MeA & $N A$ & $N A$ & $F=M$ & $N A$ & $F=M$ \\
SON & $N A$ & $N A$ & $F<M$ & $F=M$ & $F>M^{*}$ \\
Pe & $N A$ & $N A$ & $N A$ & $N A$ & $F>M$ \\
\hline
\end{tabular}


Table 2 Esr2 mRNA expression in postnatal (PND 0 to PND 2) rat brain with neonatal BPA exposure.

\begin{tabular}{llcccc}
\hline & & Vehicle & EB & LBPA & HBPA \\
\hline BNSTp & PND 4 & $F=M$ & $F=M$ & $F=M$ & $F=M$ \\
& PND 10 & $F=M$ & $\downarrow F=M$ & $F>M \Downarrow$ & $\downarrow F<M$ \\
PVN & PND 4 & $F=M$ & $\downarrow F=M \Downarrow$ & $F=M$ & $F=M \Downarrow$ \\
& PND 10 A & $F<M$ & $\downarrow F=M \Downarrow$ & $F>M \Downarrow$ & $F=M$ \\
& PND 4 & $F=M$ & $\downarrow F=M$ & $\downarrow F=M$ & $\downarrow F=M$ \\
SON & PND 10 & $F=M$ & $F=M$ & $N A$ & $F=M \Downarrow$ \\
& PND 4 & $F=M$ & $F=M$ & $F=M \Downarrow$ & $F=M \Downarrow$ \\
& PND 10 & $F=M$ & $F=M$ & $F=M$ & $\downarrow F=M \Downarrow$ \\
\hline
\end{tabular}

' $\downarrow$ ' and ' $\Downarrow$ ' represent signal significantly decreased compared with vehicle control or PND 0 female and male respectively. ${ }^{*} P=0.07$ from $t$-test between female and male on PND 19. NA, analysis is not available.

\section{$L H b$}

In the LHb, Esr2 mRNA was visible from PNDs 0-19 in both sexes on both the autoradiograms and the emulsion-dipped slides (Fig. 4). Comparison with adjacent sections labeled for Esr1 confirmed that no cross reactivity occurred and that, although weak, the signal is exclusively Esr2 and not Esr1 (Fig. 4A, B, C and D) until PND 19. In a few PND 19 animals, a very weak signal for Esr1 was observed on the autoradiograms and confirmed by silver grain deposition (Fig. 4E and F). Signal was insufficient for quantification but qualitatively it appears that there may be a sex difference in Esr2 expression during PNDs 0-4 but not after.

\section{Experiment 2: impact of neonatal BPA exposure on postnatal Esr2 expression}

For Experiment 2, Esr2 signal was quantified on PNDs 4 and 10 in the BNSTp, PVN, SON, and MeA (Figs 5, 6 and 7). Signal was not robust enough to quantify the expression in the SCN or LHb.

\section{BNSTp}

In the PND 4 animals, two-way ANOVA did not reveal a significant effect of sex, exposure group, or a significant interaction for Esr2 expression (Fig. 5 and Table 1). On PND 10, two-way ANOVA revealed a significant effect of exposure group $(F(3,35)=29.15, P \leq 0.001)$ and an interaction with sex $(F(3,35)=19.22, P \leq 0.01)$. Oneway ANOVA within females revealed an overall effect of exposure $(F(3,20)=11.71, P \leq 0.0001)$, with both $E B$ $(P \leq 0.05)$ and HBPA $(P \leq 0.01)$ significantly decreasing Esr2 expression (Fig. 5C and D). In the PND 10 males, the main effect of exposure did not quite reach statistical significance $(F(3,15)=3.169, P=0.055)$, but the Dunnett's post hoc test revealed that Esr2 expression was lower in the LBPA exposure group compared with the same-sex, unexposed controls $(P \leq 0.05)$.

\section{PVN}

Two-way ANOVA indicated a significant effect of exposure $(F(3,40)=8.12, P \leq 0.0002)$ on PND 4 (Fig. 6), but no effect of sex or a significant interaction.
EB significantly decreased Esr2 signal in both sexes $(P \leq 0.05)$, while HBPA decreased Esr2 signal only in males (Fig. 6A and B). On PND 10, two-way ANOVA revealed a significant effect of exposure $(F(3,40)=$ $8.087, P \leq 0.0002)$ and a significant interaction with sex $(F(3,40)=4.742, P \leq 0.0064)$. As expected, on PND 10 a sex difference in Esr2 expression was observed in the vehicle controls, with higher levels in males (Fig. 6C and D). EB exposure decreased Esr2 mRNA expression in both sexes, thereby eliminating the sex difference. In the LBPA group, expression was significantly lower in males $(P \leq 0.05)$ and higher in females $(P \leq 0.044)$, compared with their same-sex controls, which reversed the sex difference in expression $(P \leq 0.05)$. Expression in the HBPA group was not significantly altered in either sex compared with their control conspecifics, but altered enough such that the sex difference in expression was lost (Fig. 6D).

\section{$M e A$}

Esr2 expression was not sexually dimorphic on PND 4 or 10 (Table 1 and Fig. 7A, E, F and G). In the PND 4 animals, two-way ANOVA revealed a significant effect of exposure $(F(3,45)=6.766, P \leq 0.0007)$ and sex $(F(1,45)=4.971, \quad P \leq 0.03)$. EB $(P \leq 0.01)$, LBPA $(P \leq 0.01)$, and HBPA $(P \leq 0.05)$ all significantly decreased Esr2 mRNA levels in females (Fig. 7A and E), which collectively accounted for the main effect of sex. On PND 10, only one sample from the male LBPA exposure group was available, so the data are presented for qualitative assessment only. One-way ANOVA indicated no exposure effect in females (ANOVA not performed in males). In males, a $t$-test revealed that Esr2 signal was significantly lower in the HBPA males $(P \leq 0.05)$ compared with the vehicle controls.

\section{SON}

On PND 4, Esr2 expression in the SON was sexually dimorphic in the vehicle controls, with higher levels in males $(P \leq 0.05)$. Two-way ANOVA identified a significant effect of exposure $(F(3,42)=4.642, P \leq 0.007)$ and a significant interaction with sex $(F(3,42)=3.265$, $P \leq 0.03)$. Both doses of BPA, but not $\mathrm{EB}$, significantly decreased Esr2 mRNA levels in males $(F(3,22)=5.652$, 


\section{BNSTp}
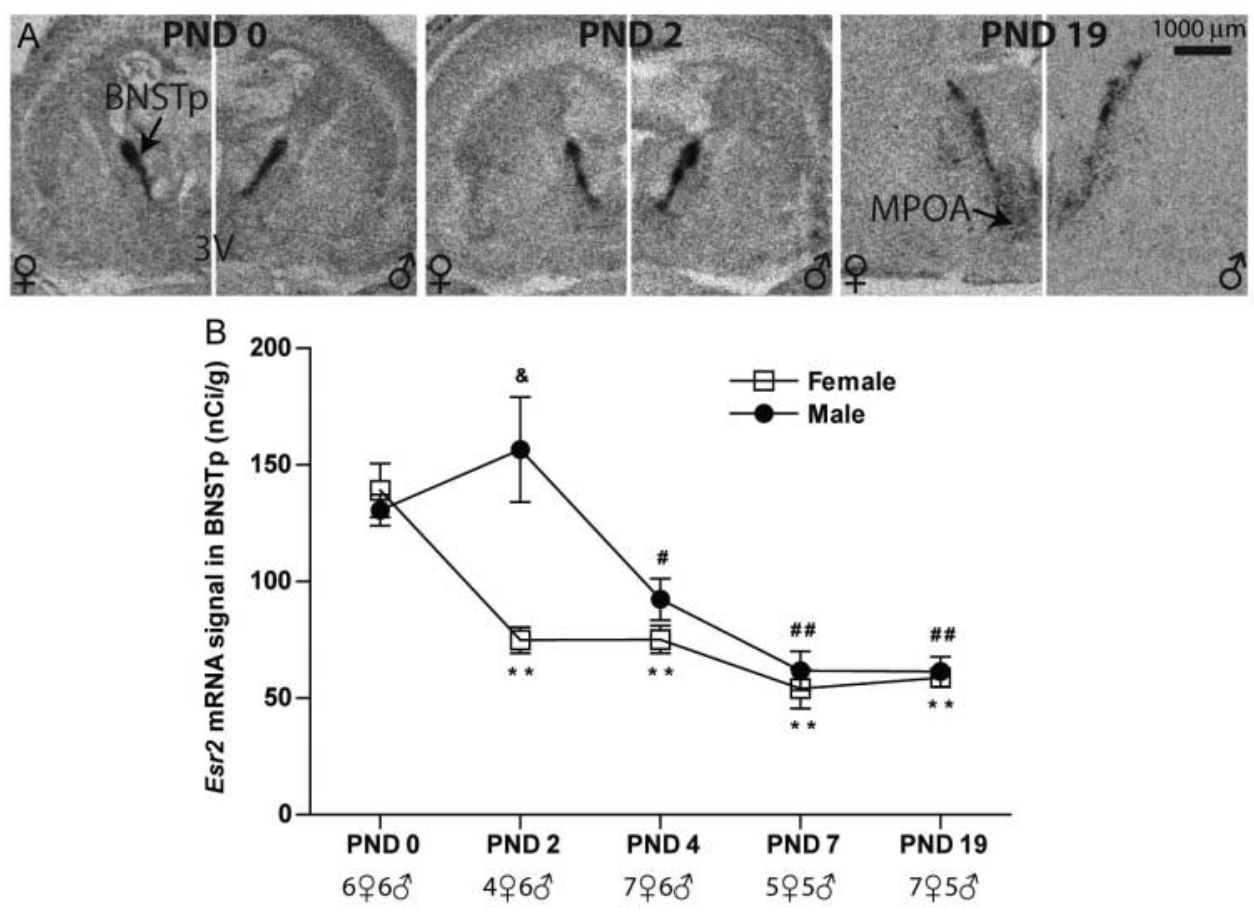

PVN
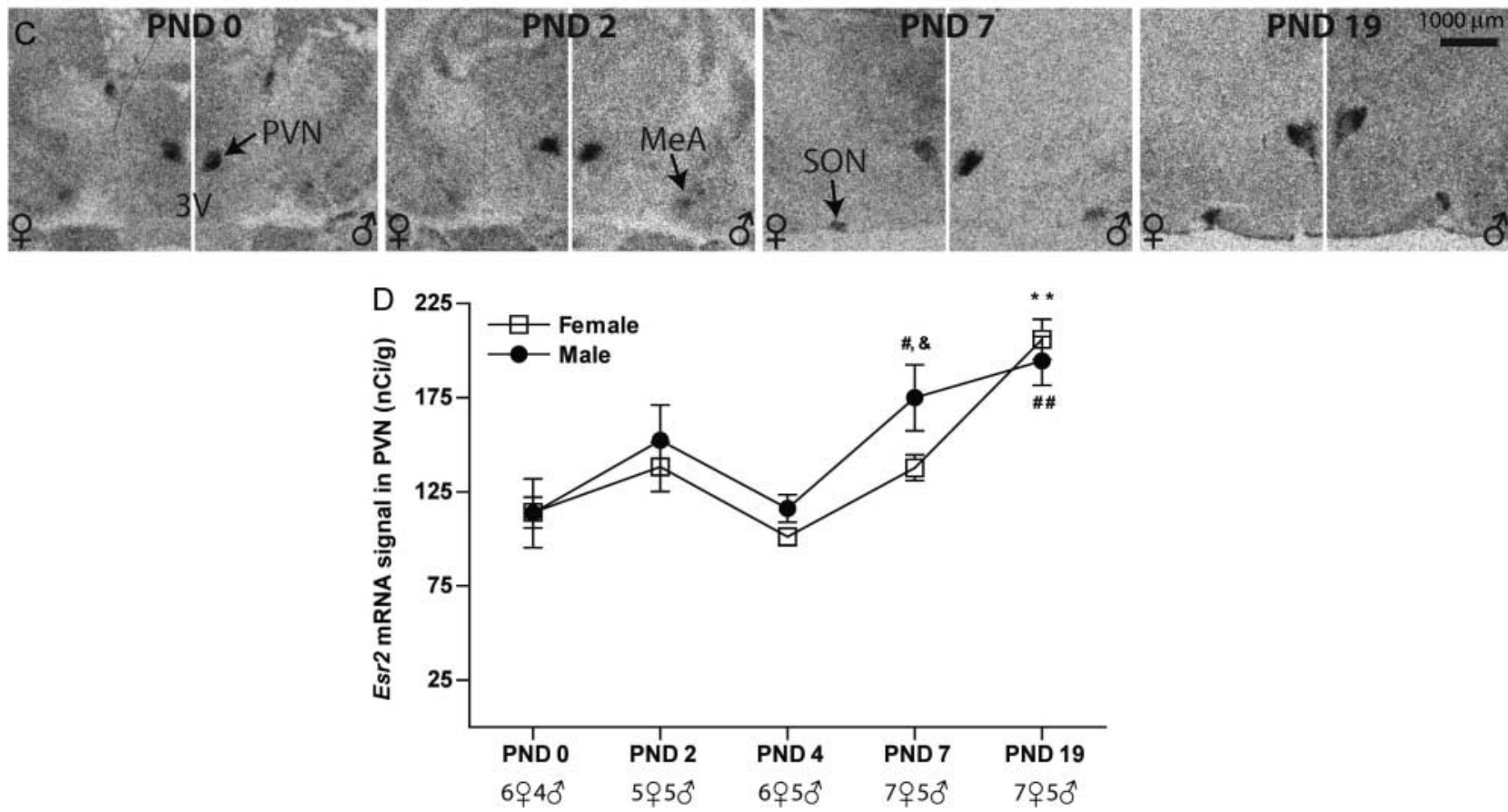

Figure 2 Autoradiographic images showing Esr2 mRNA signal in the postnatal rat BNSTp (A) and PVN (C) of both sexes (females on left side, males on the right in each panel). Within the BNSTp, labeling was robust at birth and declined by PND 2 in females and PND 4 in males, and remained low PND 19 (A and B). In PVN, Esr2 mRNA signal was high on the day of birth and unchanged through PND 4 (C and D). On PND 7, Esr2 signal was significantly increased in males only, and thus showed a sexually dimorphic expression pattern. By PND 19, Esr2 mRNA levels were equivalent in both sexes (C and D). Significant differences in expression compared with PND 0 levels are represented by ${ }^{* *} P \leq 0.01$ for the females, and ${ }^{\sharp} P \leq 0.05$ and ${ }^{\# \#} P \leq 0.01$ for the males. Sex differences in expression at each age are represented by ${ }^{\circledR} P \leq 0.05$. The sample size for each group is presented in the graphs, and the bar in graphs represents mean \pm s.E.M. For abbreviations, see list. Scale bar is $1000 \mu \mathrm{m}$ for all images in A and C. 
A
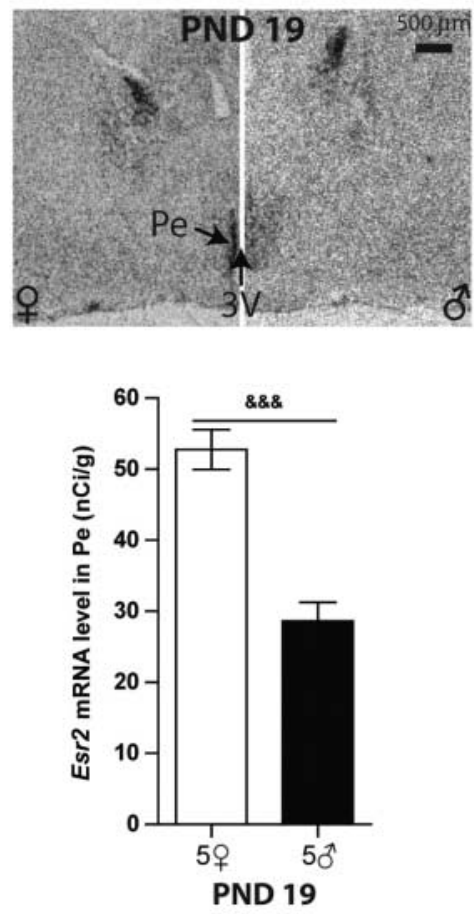

C
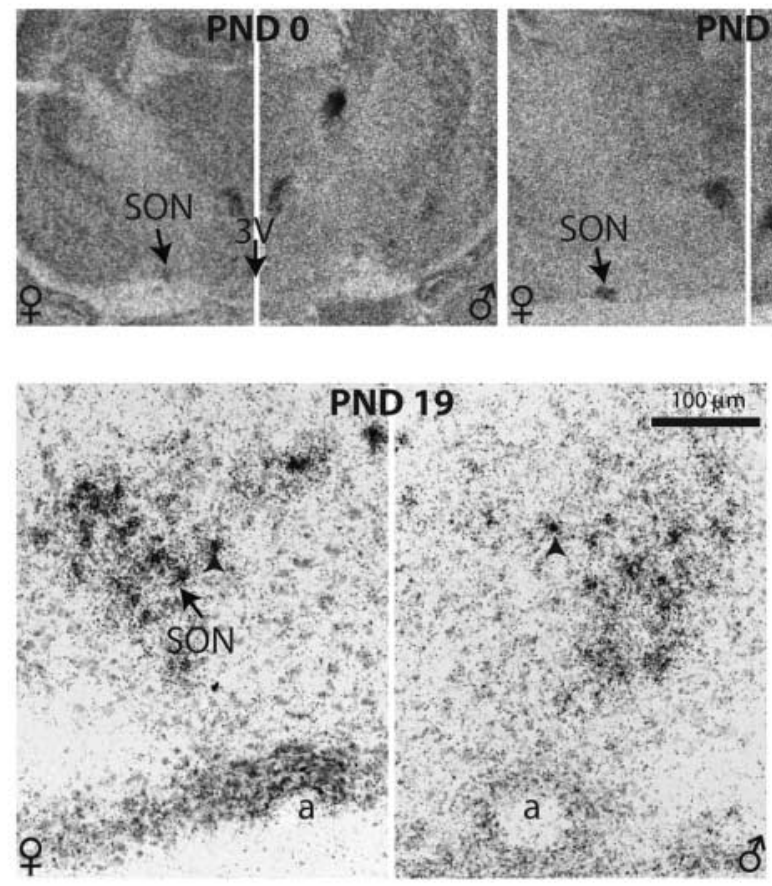

SON
B
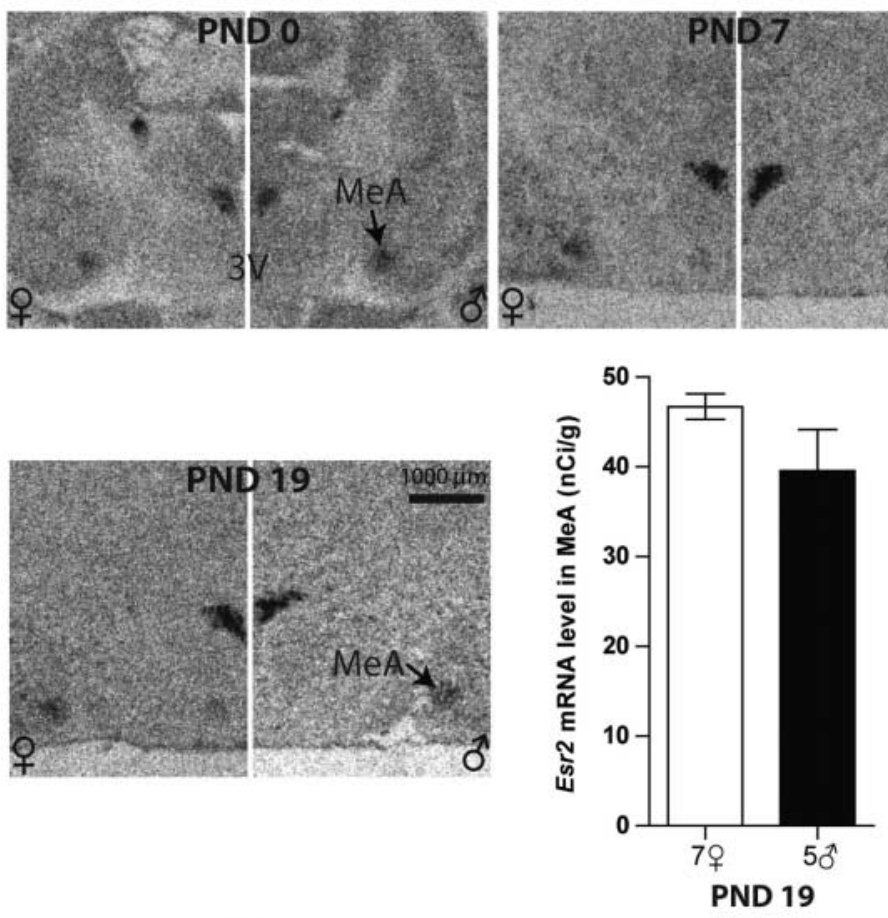
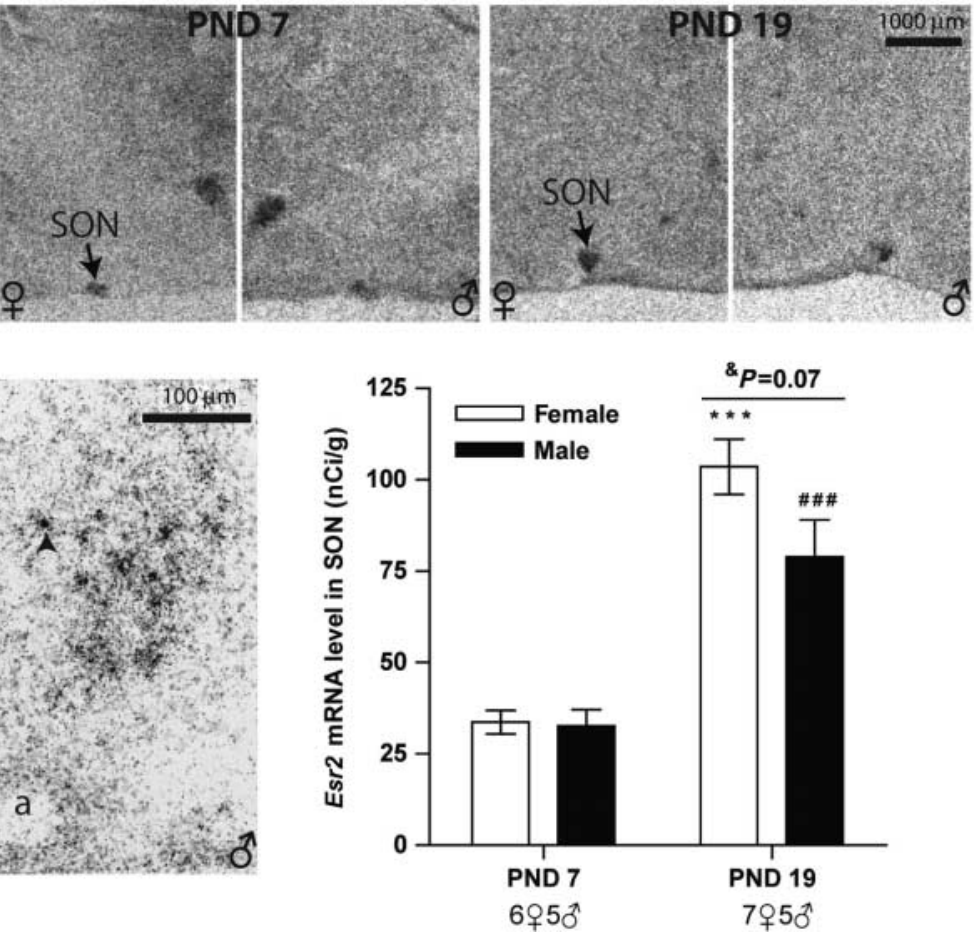

Figure 3 Autoradiographs depicting Esr2 mRNA labeling in the Pe (A), MeA (B), and SON (C) of both sexes (females in the left panel, males in the right panel). In Pe, Esr2 mRNA signal was higher in females than in males on PND 19 (A) but too weak to quantify at earlier ages. Similarly, Esr2 signal could only be quantified in the PND $19 \mathrm{MeA}$, and no sex difference was observed (B). Esr2 signal in SON was relatively weak before PND 7 (C), but increased from PND 7 to PND 19 in both sexes with a marginal $(P=0.07)$ sex difference emerging on PND 19 (C). Silver grain deposition on the emulsion-dipped slides confirmed the presence of distinct Esr2 signal in the SON (bottom left panel in C). Significant differences in gene expression are represented by ${ }^{* * *} P \leq 0.001$ for the females and ${ }^{\# \#} P \leq 0.001$ for the males compared with the levels observed for PND 7 . Significant sex differences are represented by ${ }^{\& \& \&} P \leq 0.001$. The graphs depict mean \pm s.E.M. and the sample size is provided for each age. For abbreviations, see list. Scale bar is labeled in each panel. 

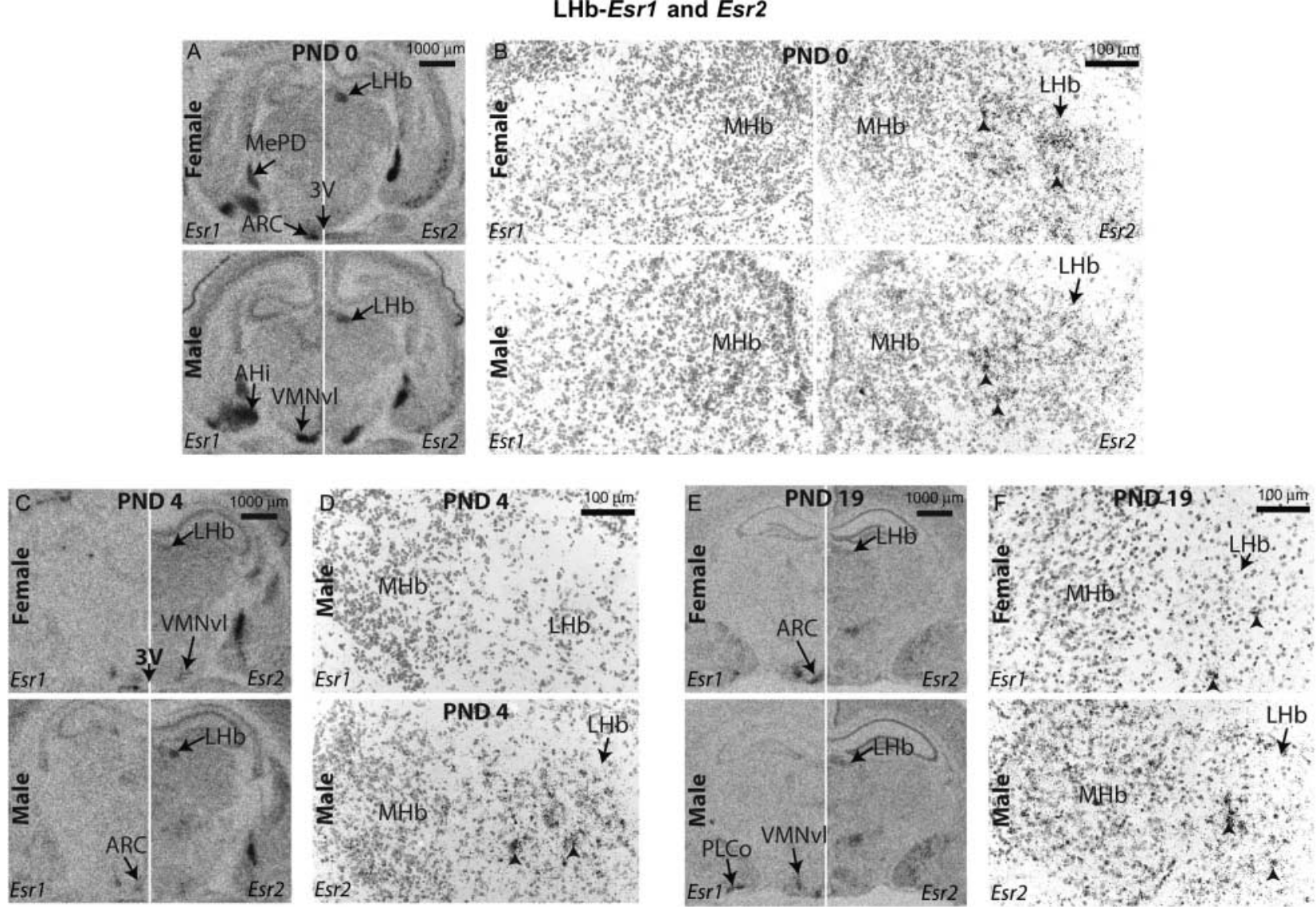

Figure 4 Representative autoradiographic images, and silver grain deposition of Esr2 (right panel of A, B, C and E) and Esr1 (left panel of A, B, C and E) signal in both sexes on PND 0, 4, and 19 demonstrating that the Esr expression in this region is exclusively the Esr2 subtype. On the day of birth, Esr2 signal was robust in both females (A, top right panel) and males (A, bottom right panel), no Esr1 mRNA labeling was appreciable in either sex (left panel of A). Silver grain deposition confirmed the film results in both females (B, left for Esr1 and right for Esr2 on top) and males (B, left for Esr1 and right for Esr2 on bottom). Qualitatively, Esr2 mRNA signal appeared to decrease with age in both sexes (right panels of $\mathrm{C}$ and E), and silver grain deposition ( $\mathrm{D}$ and $\mathrm{F}$ ) suggested decreased number of cells containing signal and decreased expression levels within labeled cells. Esr1 mRNA signal was not observed on either the films or the emulsion-dipped slides from PND 0 to 7 (left panel of A, B, C, and E, D and bottom panel of F) in sequential sections, from the same animals, used to label Esr2. By PND 19, a very weak Esr1 signal was observed on the autoradiographs in a subset of animals, and silver grain deposition confirmed it with only a small number of silver grains clusters appreciable (top panel of F). Signal strength was insufficient to quantify either Esr1 or Esr2. Arrows indicate silver grain clusters. The scale bar is labeled in each panel.

$P \leq 0.005)$, but the sex difference in expression was lost in all three groups (Fig. 7A, B and Table 1). On PND 10, two-way ANOVA only indicated an effect of exposure $(F(3,38)=4.746, P \leq 0.007)$. Esr2 signal was significantly lower compared with same sex conspecifics in the HBPA group $(P \leq 0.05$, Fig. $7 \mathrm{C}$ and $\mathrm{D})$.

\section{Discussion}

These data are significant in that they i) constitute the most detailed mapping of Esr2 expression in the BNSTp, PVN, SON, MeA, SCN, and LHb during the first 2 weeks of life, and ii) show that neonatal BPA exposure can suppress Esr2 expression in sexually dimorphic brain regions fundamental to sociosexual behavior. Across postnatal development, Esr2 expression was region and sex-specific, and significantly changed with age.
Accordingly, effects of neonatal BPA exposure were age, region, and sex-specific. These studies are the first to show that neonatal BPA exposure can perturb Esr2 expression in the BNSTp, PVN, MeA, and SON. In all cases except the PND 10 female PVN, expression was reduced by $\mathrm{BPA}$, and $\mathrm{EB}$-related effects were directionally similar. These observations are consistent with our prior observations comparing the region-specific impact of BPA and exogenous estrogen on Esr expression in limbic subnuclei (Cao et al. 2012, 2013), and emphasize that BPA may not be simply acting as an estrogen mimic in the brain. Diminished Esr expression by BPA presumably results in reduced regional sensitivity to endogenous estrogen, thereby altering estrogendependent neural organization. Although the functional significance of disrupted postnatal Esr expression remains to be fully established, altered postnatal Esr 
PND 4-BNSTp
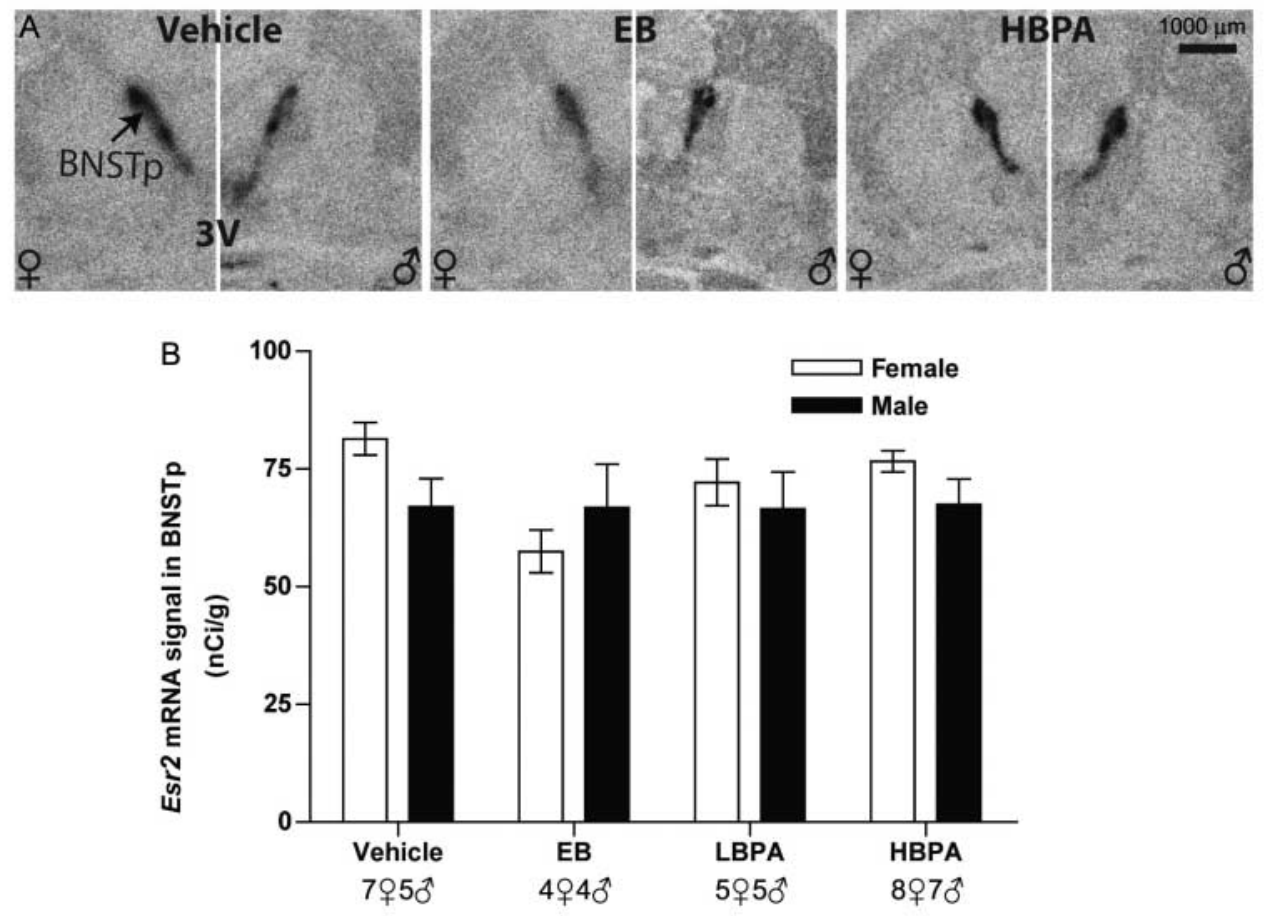

PND 10-BNSTP
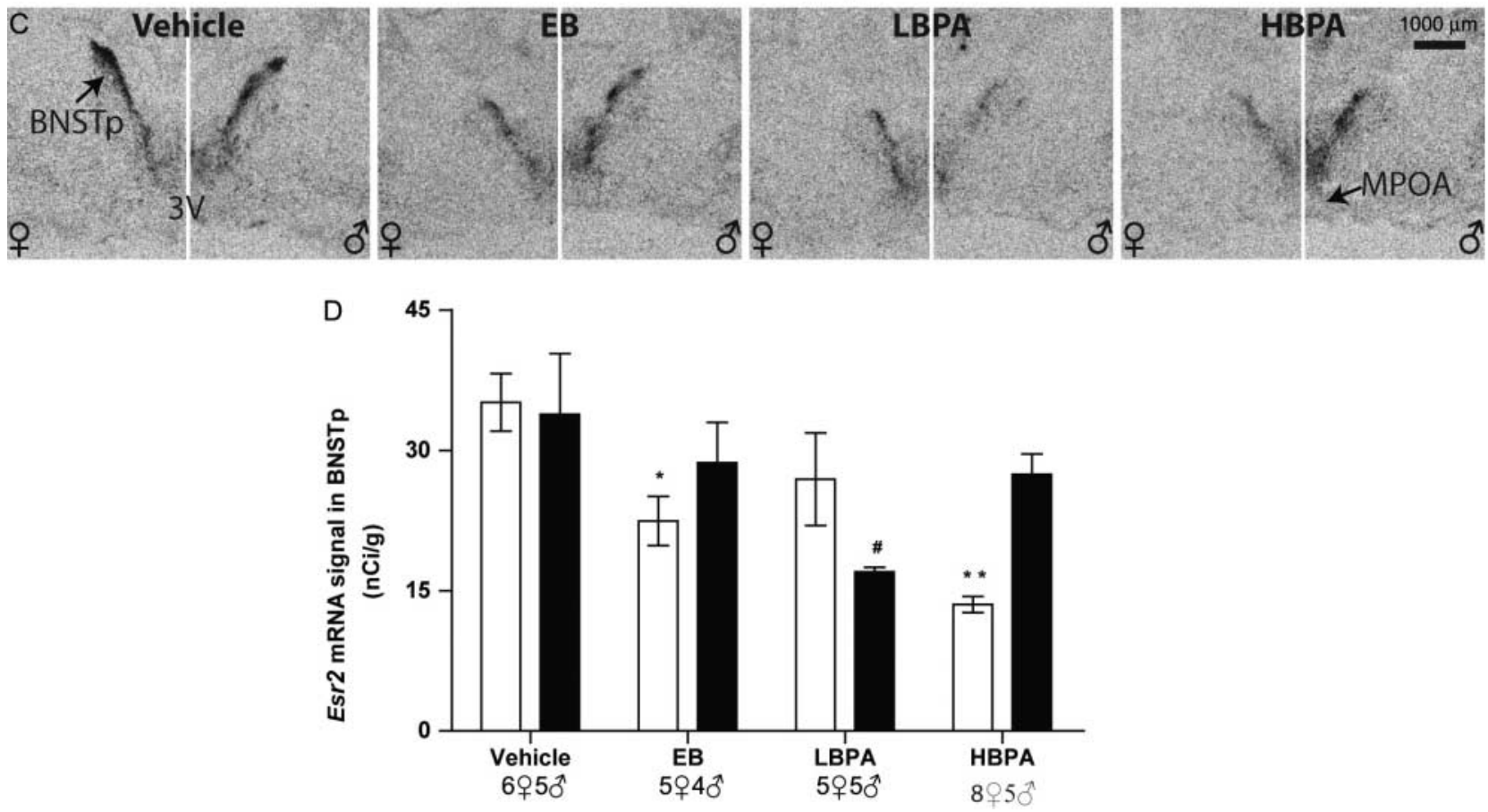

Figure 5 Representative autoradiographs of Esr2 signal in the BNSTp on PND 4 (A) and PND 10 (C) after vehicle (OIL), EB, LBPA, and HBPA exposure (from left to right in both A and C). Optical density analysis of Esr2 expression in the PND 4 (B) and the PND 10 (D) BNSTp showed that Esr2 expression was significantly decreased in females on PND 4 and 10 by neonatal EB exposure (B and D, left panels). BPA had no effect in either sex on PND 4 (C) and on PND 10, reduced Esr2 mRNA levels were observed in LBPA males, but not in LBPA females, while the reverse was true in HBPA animals (D). Significant differences in expression compared with vehicle are represented by ${ }^{*} P \leq 0.05,{ }^{* *} P \leq 0.01$ for the females, and ${ }^{*} P \leq 0.05$ for the males. The graphs depict mean \pm S.E.M. and the sample size is provided at the bottom ( $3 \mathrm{~V}$, third ventricle; scale bar $=1000 \mu \mathrm{m}$ ). 


\section{PND 4-PVN}
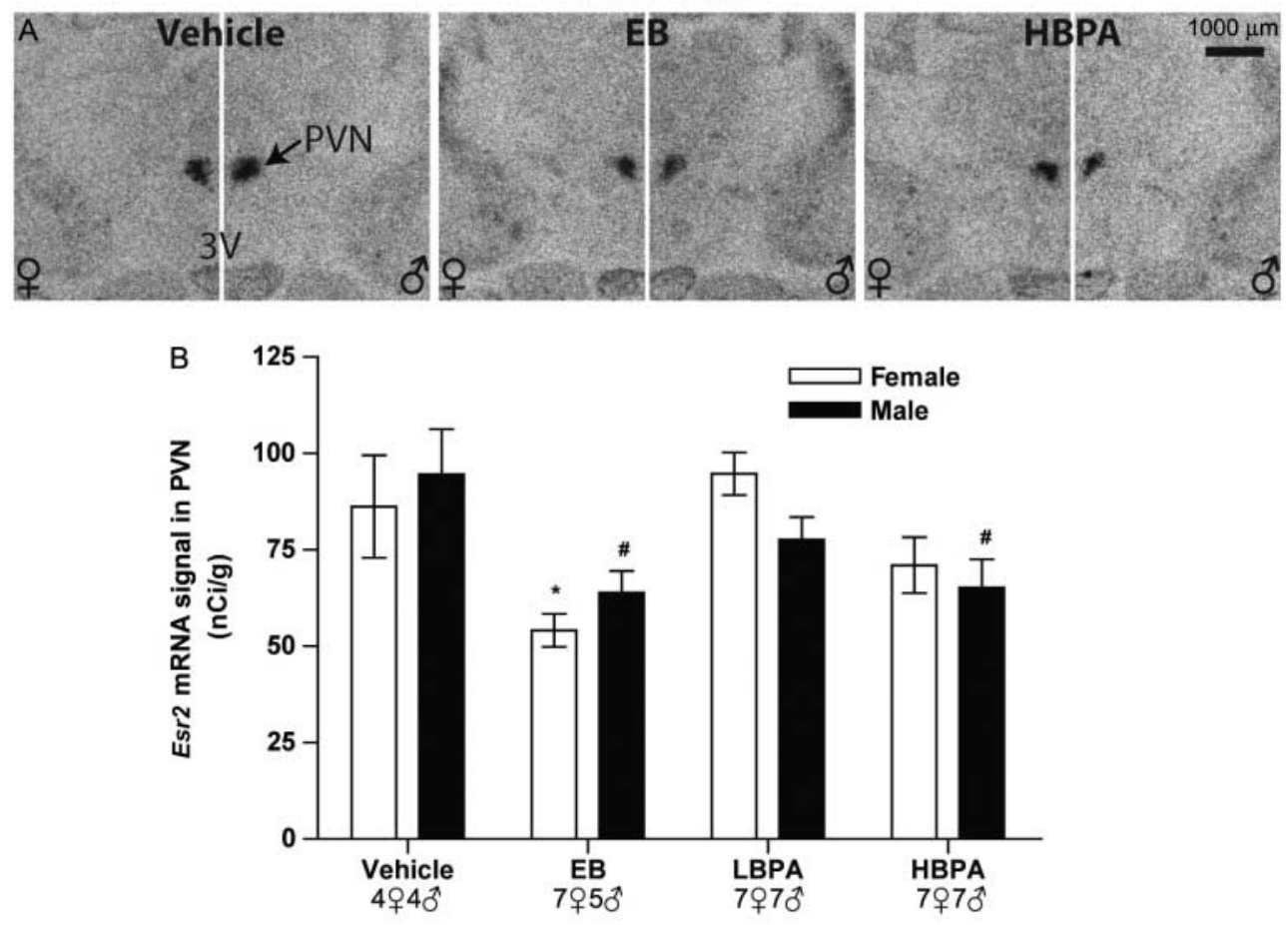

PND 10-PVN
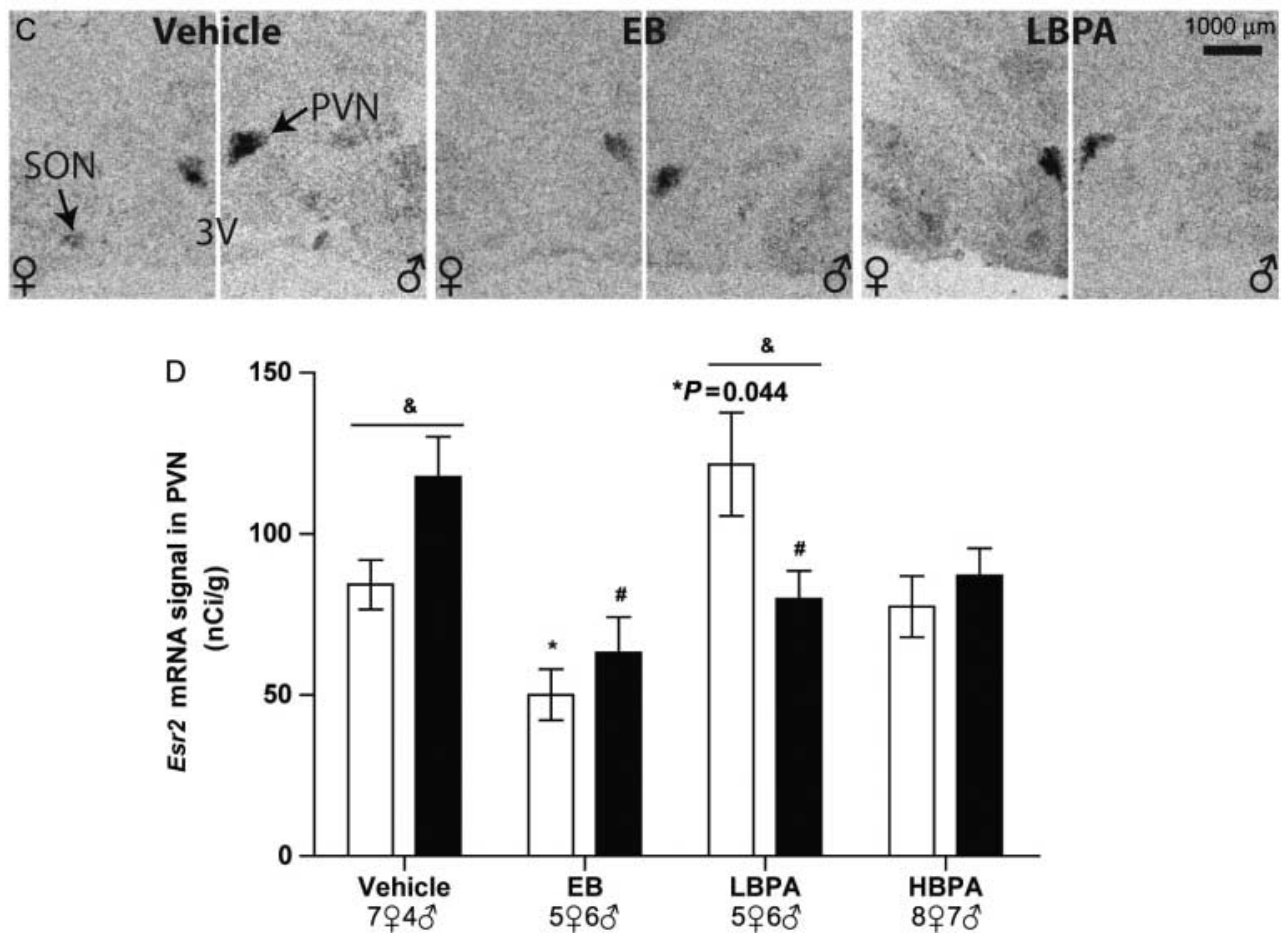

Figure 6 Autoradiographs depicting Esr2 signal in the PVN on PND 4 (A) and on PND 10 (C) after neonatal vehicle (OIL), EB, LBPA, and HBPA exposure (from left to right in both A and C). Reduced Esr2 expression following neonatal EB exposure was observed in both sexes on PND 4 (B) and PND 10 (D), which eliminated the expected sex difference in expression on PND 10. BPA only significantly impacted Esr2 expression in males. On PND 4, expression was slightly, but significantly decreased in the HBPA males (B). At PND 10, expression was abrogated in the LBAP males which effectively reversed the expected sex difference in expression compared with vehicle controls (D). Significant differences in expression compared with vehicle are represented by $* P \leq 0.05$ for the females, and ${ }^{\#} P \leq 0.05$ for the males. Significant sex differences in expression are represented by ${ }^{\&} P \leq 0.05$. The graphs depict mean \pm s.E.M. and the sample size is provided at the bottom ( $3 \mathrm{~V}$, third ventricle; scale bar $=1000 \mu \mathrm{m})$. 
levels within the developing brain ostensibly contributes to reported deficiencies in adult sociosexual physiology and behavior in both sexes (NTP 2008, FAO/WHO 2011, Wolstenholme et al. 2011, Losa-Ward et al. 2012, Rochester 2013). These data also support the hypothesis posed by us (Adewale et al. 2011 \#2520) (Patisaul et al. 2012 \#2605) and others (Wolstenholme et al. 2012 \#2561; Wolstenholme et al. 2011 \#2366) that BPA exposure may perturb the organization of OT/AVP signaling pathways.

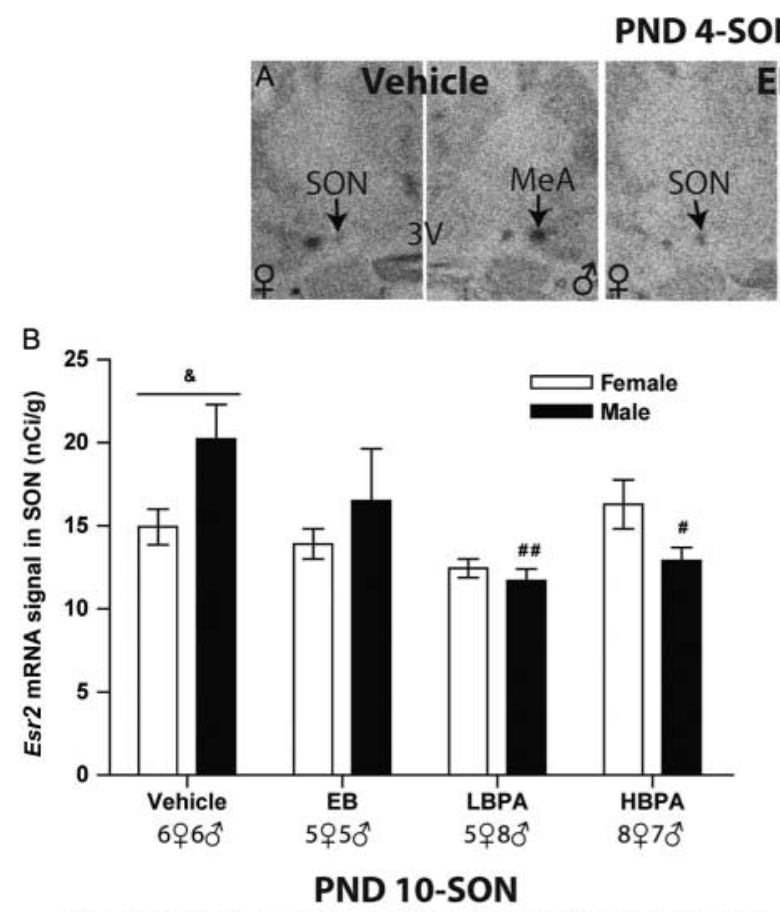

and MeA
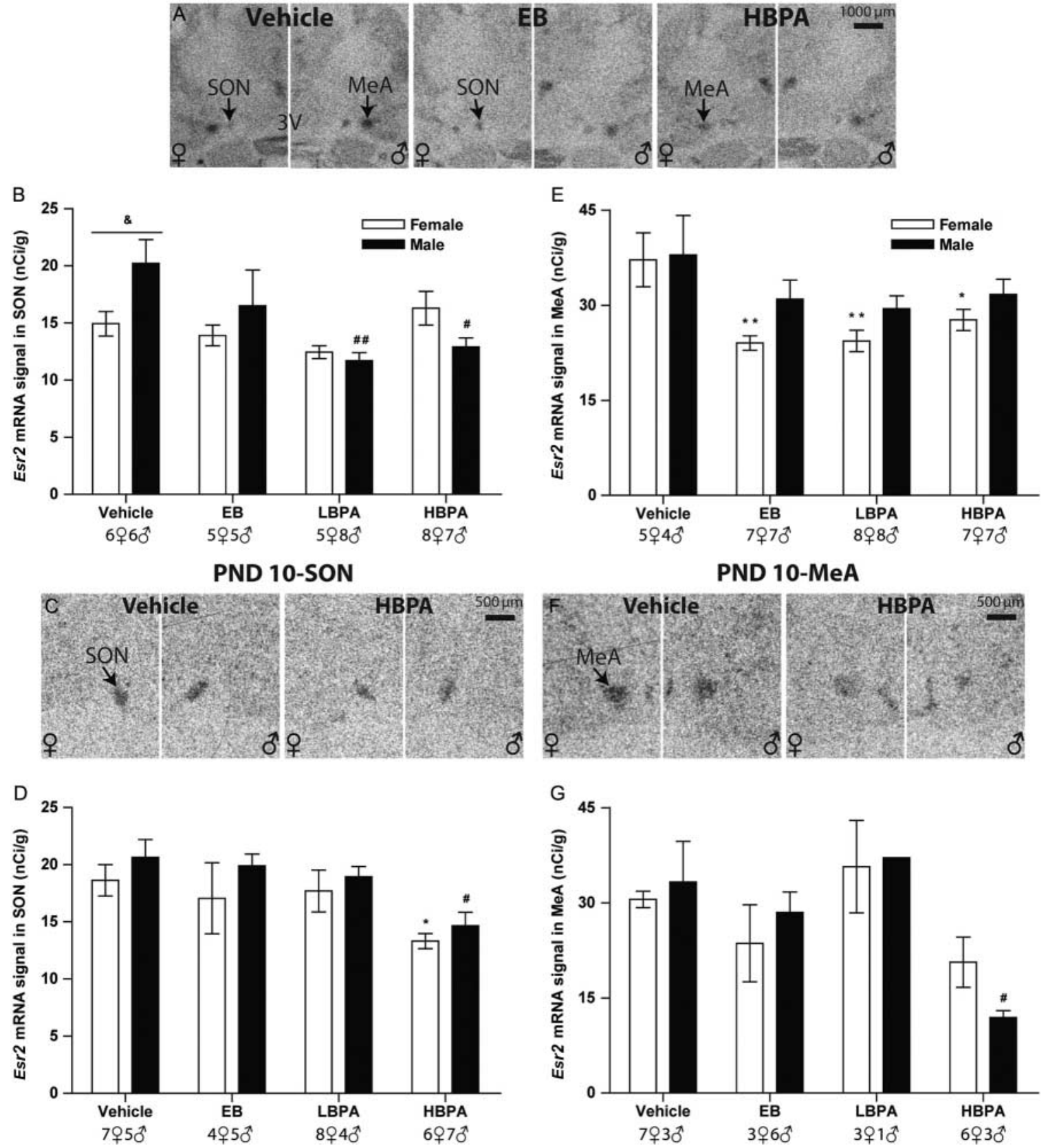

Figure 7 Autoradiographs depicting Esr2 signal in the SON and MeA on PND 4 (A) and in the SON (C) and MeA (F) on PND 10. In the SON, EB had no significant effect on Esr2 expression in either sex, although the levels were no longer distinct enough to be significantly sexually dimorphic. Both doses of BPA decreased Esr2 signal in PND 4 males, thus diminishing the expected sex difference in expression on PND 4 (B). On PND 10, Esr2 levels were slightly but significantly decreased in both sexes of the HBPA group (D). In the MeA, EB and both doses of BPA decreased Esr2 mRNA levels in PND 4 females (E). By PND 10, decreased expression emerged in the HBPA males (G). Effects in the LBPA males were not statistically analyzed due to insufficient sample size. Significant differences in expression compared with vehicle are represented by $* P \leq 0.05$ and $* * P \leq 0.01$ for the females, and ${ }^{\#} P \leq 0.05$ and ${ }^{\# \#} P \leq 0.01$ for the males. Significant sex differences in expression are represented by ${ }^{\&} P \leq 0.05$. The graphs depict mean \pm s.E.M. and the sample size is provided at the bottom ( $3 \mathrm{~V}$, third ventricle; scale bar $=1000 \mu \mathrm{m}$ for $\mathrm{A}$, and $500 \mu \mathrm{m}$ for $\mathrm{C}$ and $\mathrm{F}$ ). 
As anticipated, based on prior work by us and others (Kuhnemann et al. 1994, Yokosuka et al. 1997, Perez et al. 2003, Cao \& Patisaul 2011, 2013), both Esrs were robustly expressed throughout the hypothalamus and surrounding regions on the day of birth, and then diverged in temporal and sexually dimorphic patterns. Importantly, these studies reveal that expression patterns in pre-weanling rats differ from the expression patterns in adults to some degree. In adult rodents, both Esr subtypes are present in the BNSTp and MeA (Simerly et al. 1990, Kuhnemann et al. 1994, Shughrue et al. 1997 b, Yokosuka et al. 1997, Laflamme et al. 1998, Osterlund et al. 1998, Shughrue \& Merchenthaler 2001, Perez et al. 2003, Cao \& Patisaul 2011, 2013), whereas Esr2, but not Esr1, is present in the adult PVN, SON, and SCN (Shughrue et al. 1997a, 1997b, Osterlund et al. 1998, Mitra et al. 2003). Esr1 is the predominant isoform in the arcuate nucleus (ARC) and Pe (Shughrue et al. 1997b, Yokosuka et al. 1997, Laflamme et al. 1998, Osterlund et al. 1998, Cao \& Patisaul 2011, 2013), and is exclusively expressed in the adult SCN and LHb (Laflamme et al. 1998, Vida et al. 2008). In this study, sex differences in Esr2 expression were observed in the Pe and, to a lesser degree, the SON, on PND 19 with expression higher in females. These differences are consistent with morphological and functional sex differences associated with these regions in adults. For example, the volume of SON is larger in adult males than in age-matched female rats (Madeira et al. 1993), and the Pe is a component of the region controlling the prenatal gonadotropin surge in females (Mikkelsen \& Simonneaux 2009, Poling et al. 2013).

The expression patterns were more complex in the BNSTp and PVN. Across postnatal development Esr2 expression levels generally decreased in the BNSTp but increased in the PVN. Transient sex differences in Esr2 expression were observed in the BNSTp and PVN (which were lost by PND 19), with males having higher levels than females. Interestingly, a temporary sex difference in Esr1 expression has also been reported in the rat BNSTp. The levels were observed to be higher in females on PND 6, but this difference was lost on PND 19 and then robustly re-established in adulthood (Kelly et al. 2013). In adult BNSTp, both Esr1 (Kelly et al. 2013) and Esr2 (Zhang et al. 2002) expression levels are higher in females. These brief sex differences in expression may contribute to BNSTp-related morphological and functional sex differences found later in life. For example, sex differences in BNSTp volume, cell number, and cell size begin to emerge around PND 7 and result from suppression of cell death in males by estrogen (Murray et al. 2009, Hisasue et al. 2010, Ahern et al. 2013).

Qualitatively, low levels of Esr2 mRNA were observed in the postnatal SCN of both sexes at all ages and Esr2 expression was appreciable in the LHb from PND 0-7, then diminished to near the limit of detection by PND 19. Examination of adjacent sections (Cao \& Patisaul 2011) revealed minimal signal for Esr1 in the PND 19
LHb but no Esr1 signal before that, or at any age in the $\mathrm{SCN}$, suggesting that Esr2 is the predominant Esr isoform expressed in these two regions during postnatal development. The $\mathrm{LHb}$ is an important regulatory site of both the midbrain dopamine and dorsal raphe serotonin systems, and integrates information from limbic nuclei (such as the BNSTp and Me) (Reisine et al. 1982, Christoph et al. 1986, Lecourtier \& Kelly 2007, Hikosaka et al. 2008) central to reproductive and maternal behavior (Lonstein et al. 2000). Previous studies using ovariectomized animals have concluded that only Esr1 is expressed in the postnatal rat LHb (Yokosuka et al. 1997, Laflamme et al. 1998, Perez et al. 2003, Vida et al. 2008), but at least one has reported the presence of both isoforms (Shughrue et al. 1997b). In addition to gonadal status, strain differences may also account for the discrepancies between previous studies and the present one.

Neonatal exposure to BPA altered postnatal Esr2 expression in the BNSTp, SON, MeA, and PVN. When collectively considered with our previous companion study exploring BPA-related Esr expression changes in neighboring subnuclei (Cao et al. 2012), the data support the hypothesis that one way in which BPA may alter the sex-specific ontogeny of neuroendocrine systems is via perturbation of Esr levels in sexually dimorphic brain regions. Differences in local estrogen levels, derived from gonadal androgens in males or synthesized de novo (Amateau et al. 2004), likely at least partially account for the regional specificity of the effects. The observed gene expression changes could reflect either a change in cellular levels of Esr2 mRNA within each ROI or a change in the number of cells expressing Esr2, the latter of which would suggest that the effect is permanent (McCarthy 2008). Similar studies from our laboratory revealed no significant effects of neonatal BPA ( $50 \mu \mathrm{g} / \mathrm{kg}$ bw or $50 \mathrm{mg} / \mathrm{kg}$ bw) exposure on Esr1 neuron numbers in the anterior or MBH in adulthood (Patisaul et al. 2007, Adewale et al. 2011), suggesting that disruption of neonatal Esr expression may not manifest as Esr neuron loss. Ongoing work in our laboratory is seeking to establish the degree to which BPA-related Esr expression level changes persist, if they are accompanied by altered OT/AVP expression changes, and associated with neurobehavioral effects such as altered anxiety (Sullivan et al. 2011, Patisaul et al. 2012).

Although the BPA doses and route of exposure employed for these studies are not considered human relevant, through work conducted in collaboration with researchers at the National Center for Toxicological Research (NCTR) we have previously shown that oral BPA exposure to the pregnant dam, across a range of environmentally relevant doses (2.5 or $25 \mu \mathrm{g} / \mathrm{kg}$ bw), downregulates $E s r$ expression in the neonatal rat hypothalamus and amygdala (Cao et al. 2013). In addition, at weaning, the volume of the sexually dimorphic nucleus of the POA (SDN-POA) was significantly larger in the BPA-exposed males, compared with 
unexposed conspecifics (He et al. 2012). As in the BNSTp, the male SDN is protected from cell death by estrogens derived from gonadal androgens, and is thus larger in males than in females. Enhancement of SDN size by BPA exposure is consistent with an estrogenic mode of action. The health effects of low dose oral exposure remain the subject of considerable interest because human exposure is presumably low but constant and from a variety of sources including food, beverages, the handling of paper receipts, and dust (Vandenberg et al. 2007, Biedermann et al. 2010, Lakind \& Naiman 2010). Our results suggest that one possible outcome may be altered Esr2 expression in steroidhormone-sensitive regions of the developing brain, an effect which may have long-term consequences on sociosexual and mood-related behaviors. Further work is needed to better establish if these effects can be induced via exposures that better recapitulate human exposure conditions and doses.

Elucidating the specific mechanisms by which BPA affects neural organization is fundamental for effectively evaluating whether effects observed in rodents can be extrapolated to humans. In humans, the period encompassing the rodent perinatal period is believed to occur in mid to late gestation (Selevan et al. 2000, Simerly 2002, Aksglaede et al. 2006, Abbott et al. 2008); thus, the rat perinatal 'critical window' is likely to be entirely prenatal in humans. The possible health consequences of BPA exposure remain controversial (Goodman et al. 2009, Vandenberg et al. 2009, Beronius et al. 2010), but there is growing concern that early-life exposure may alter neural development and ultimately contribute to neurobehavioral disorders in humans (vom Saal et al. 2007, Chapin et al. 2008, NTP 2008, Palanza et al. 2008, Patisaul \& Polston 2008, Report of Joint FAO/WHO Expert Meeting 2011, Wolstenholme et al. 2011, Rosenfeld 2012). Weight of evidence assessments have been conducted by numerous groups, but conclusions regarding the degree of concern that consumers should have about BPA have been inconsistent (vom Saal et al. 2007, NTP 2008, Hengstler et al. 2011). This study is novel because it provides new insight as to how BPA may be influencing brain organization. Although there are critical species differences specific to how estrogen organizes the developing brain (Resko \& Roselli 1997, McCarthy 2008), the distribution of sex-specific Esr expression is well conserved across species (including humans) (MacLusky et al. 1979, Brandenberger et al. 1997, Resko \& Roselli 1997, Kato et al. 1998, Wallen 2005, Gonzalez et al. 2007, Walker et al. 2009, Cao \& Patisaul 2013). Esr2, particularly in the PVN, is important for modulating affective and mood-related behaviors, including anxiety, aggression, and social interactions (Lund et al. 2005, Patisaul \& Bateman 2008, Handa et al. 2012). Moreover, the ROls examined in this study are critical components of AVP/OT signaling pathways and related systems crucial for mediating aspects of sociosexual behavior including affiliation and sociality (Neumann \& van den Burg 2011). Thus a potential outcome of Esr2 disruption in the ROIs examined in this study is altered anxiety and social behaviors in later life. This hypothesis is consistent with previous work in our laboratory demonstrating that oral exposure to BPA across perinatal development, at levels considered to be human-relevant, resulted in abrogated Esr2 expression in the adolescent amygdala, as well as elevated juvenile anxiety (Patisaul et al. 2012). Numerous other studies have also reported behavioral impacts of early-life BPA exposure, including elevated anxiety, in a wide range of species (Jasarevic et al. 2011, Wolstenholme et al. 2011, Rosenfeld 2012, Jasarevic et al. 2013, Kundakovic et al. 2013). In young children, developmental BPA exposure has been associated with hyperactivity and elevated anxiety (Braun et al. 2011, Harley et al. 2013) but whether BPA exposure may contribute to neurobehavioral and mood disorders remains unknown. These data contribute important information regarding the mechanisms by which BPA-related behavioral changes may emerge and implicate disruption of the AVP/OT system. This putative link should be addressed in future experimental work, and further assessments of BPArelated impacts on neurobehavior in humans should be conducted with this potential association in mind.

\section{Discussion from meeting}

Emilie Rissman (Charlottesville, USA): In your gavage studies can you examine direct 'stress' target genes such as $\mathrm{Crh}$ or $\mathrm{Gr}$ in the offspring amygdale?

Heather Patisaul (Raleigh, USA): To do that would require permission from our collaborators at NCTR (National Center for Toxicology Research). Also, to more comprehensively confirm that the gene expression changes are caused by gavage, and not the vehicle, the experiment should be replicated and include animals treated with vehicle without gavage. That control group is missing from the present experiments.

Alana Sullivan (Raleigh, USA): The animals in your first study had a soy-free diet, and you used a soy diet in the second experiment. Diet is an important factor as a possible cause of endocrine disruption.

Heather Patisaul: Diet is part of the equation that we are working on and needs further exploration. There are important differences between soy and casein diets. It is possible that the phytoestrogens in soy interfere with the BPA action. Diet is an environmental factor to consider. Some ESRs (ESR2) are sensitive to soy.

Jane Muncke (Food Packaging Forum, Zurich, Switzerland): What equipment did you use for gavage? If it was plastic, did you test for leaching of endocrinedisrupting chemicals (EDCs) into the vehicle oil?

Heather Patisaul: For our studies done in collaboration with NCTR, the gavage equipment is all metal with no plastic and it is extensively tested along with the BPA mixture, the glass bottles, the vehicle, and the inside of the gavage machine. The machine weighs the animals 
and automatically dispenses the correct amount of vehicle. There is no contamination from this equipment as far as I know.

Jane Muncke: How is the feed packaged? This might be a source of EDC migration.

Heather Patisaul: For those studies, feeding is done at NCTR and I am not sure how it is packaged on bulk arrival. For the present studies, we received the feed in cardboard boxes and I do not know if they are lined with anything that contains BPA. We did not test the feed in previous experiments, but in current, ongoing studies with NCTR the feed has been tested and not found to be contaminated.

\section{Declaration of interest}

The authors declare that there is no conflict of interest that could be perceived as prejudicing the impartiality of the research reported.

\section{Funding}

This article is based on work presented at the 7 th Copenhagen Workshop on Endocrine Disrupters, which was supported by the Danish Ministry of the Environment - Environmental Protection Agency. Publication of this special issue was supported by the Society for Reproduction and Fertility. All authors declare no formal relationship with the sponsors of the COW meeting. Funding to attend the meeting was provided by National Institutes of Environmental Health Sciences (NIEHS) grant NIH-R01-16001 and North Carolina State University (NCSU). This work was supported by NIH-R01-16001 to Dr Heather B Patisaul.

\section{Acknowledgements}

We are grateful to Katherine A McCaffrey, whose willingness to help whenever necessary was invaluable.

\section{References}

Substance monograph on bisphenol A (BPA) 2012 - reference and human biomonitoring (HBM) values for BPA in urine. Opinion of the Human Biomonitoring Commission of the German Federal Environment Agency (UBA). Bundesgesundheitsblatt, Gesundheitsforschung, Gesundheitsschutz 1215-1231.

Abbott DH, Zhou R, Bird IM, Dumesic DA \& Conley AJ 2008 Fetal programming of adrenal androgen excess: lessons from a nonhuman primate model of polycystic ovary syndrome. Endocrine Development 13 145-158.

Adewale HB, Todd KL, Mickens JA \& Patisaul HB 2011 The impact of neonatal bisphenol-A exposure on sexually dimorphic hypothalamic nuclei in the female rat. Neurotoxicology 32 38-49. (doi:10.1016/ j.neuro.2010.07.008)

Ahern TH, Krug S, Carr AV, Murray EK, Fitzpatrick E, Bengston L, McCutcheon J, De Vries GJ \& Forger NG 2013 Cell death atlas of the postnatal mouse ventral forebrain and hypothalamus: effects of age and sex. Journal of Comparative Neurology 521 2551-2569. (doi:10.1002/ cne.23298)
Aihara M \& Hayashi S 1989 Induction of persistent diestrus followed by persistent estrus is indicative of delayed maturation of tonic gonadotropin-releasing systems in rats. Biology of Reproduction $\mathbf{4 0}$ 96-101. (doi:10.1095/biolreprod40.1.96)

Aksglaede L, Juul A, Leffers H, Skakkebaek NE \& Andersson AM 2006 The sensitivity of the child to sex steroids: possible impact of exogenous estrogens. Human Reproduction Update 12 341-349. (doi:10.1093/ humupd/dml018)

Amateau SK, Alt JJ, Stamps CL \& McCarthy MM 2004 Brain estradiol content in newborn rats: sex differences, regional heterogeneity, and possible de novo synthesis by the female telencephalon. Endocrinology 145 2906-2917. (doi:10.1210/en.2003-1363)

Andersen HR, Andersson AM, Arnold SF, Autrup $H$, Barfoed $M$ Beresford NA, Bjerregaard P, Christiansen LB, Gissel B, Hummel R et al. 1999 Comparison of short-term estrogenicity tests for identification of hormone-disrupting chemicals. Environmental Health Perspectives 107 (Suppl 1) 89-108. (doi:10.1289/ehp.99107s189)

Arai Y \& Gorski RA 1968 Critical exposure time for androgenization of the developing hypothalamus in the female rat. Endocrinology 82 1010-1014. (doi:10.1210/endo-82-5-1010)

Bader MI, Wober J, Kretzschmar G, Zierau O \& Vollmer G 2011 Comparative assessment of estrogenic responses with relevance to the metabolic syndrome and to menopausal symptoms in wild-type and aromatase-knockout mice. Journal of Steroid Biochemistry and Molecular Biology 127 428-434.

Barkhem T, Carlsson B, Nilsson Y, Enmark E, Gustafsson J \& Nilsson S 1998 Differential response of estrogen receptor $\alpha$ and estrogen receptor $\beta$ to partial estrogen agonists/antagonists. Molecular Pharmacology $\mathbf{5 4}$ 105-112.

Beronius A, Ruden C, Hakansson H \& Hanberg A 2010 Risk to all or none? A comparative analysis of controversies in the health risk assessment of bisphenol A. Reproductive Toxicology 29 132-146. (doi:10.1016/ j.reprotox.2009.11.007)

Biedermann S, Tschudin P \& Grob K 2010 Transfer of bisphenol A from thermal printer paper to the skin. Analytical and Bioanalytical Chemistry 398 571-576. (doi:10.1007/s00216-010-3936-9)

Blair RM, Fang H, Branham WS, Hass BS, Dial SL, Moland CL, Tong W, Shi L, Perkins R \& Sheehan DM 2000 The estrogen receptor relative binding affinities of 188 natural and xenochemicals: structural diversity of ligands. Toxicological Sciences 54 138-153. (doi:10.1093/ toxsci/54.1.138)

Brandenberger AW, Tee MK, Lee JY, Chao V \& Jaffe RB 1997 Tissue distribution of estrogen receptors and $\alpha(E R-\alpha)$ and $\beta(E R-\beta)$ in the midgestational human fetus. Journal of Clinical Endocrinology and Metabolism 82 3509-3512. (doi:10.1210/jc.82.10.3509)

Braun JM, Kalkbrenner AE, Calafat AM, Yolton K, Ye X, Dietrich KN \& Lanphear BP 2011 Impact of early-life bisphenol A exposure on behavior and executive function in children. Pediatrics 128 873-882. (doi:10.1542/peds.2011-1335)

Brown NM \& Setchell KD 2001 Animal models impacted by phytoestrogens in commercial chow: implications for pathways influenced by hormones. Laboratory Investigation 81 735-747. (doi:10.1038/labinvest. 3780282)

Brownstein MJ 1980 Peptidergic pathways in the central nervous system. Proceedings of the Royal Society of London. Series B. Biological Sciences 210 79-90. (doi:10.1098/rspb.1980.0120)

Buijs RM, Swaab DF, Dogterom J \& van Leeuwen FW 1978 Intra- and extrahypothalamic vasopressin and oxytocin pathways in the rat. Cell and Tissue Research 186 423-433. (doi:10.1007/BF00224932)

Cabaton NJ, Wadia PR, Rubin BS, Zalko D, Schaeberle CM, Askenase MH, Gadbois JL, Tharp AP, Whitt GS, Sonnenschein C et al. 2011 Perinatal exposure to environmentally relevant levels of bisphenol A decreases fertility and fecundity in CD-1 mice. Environmental Health Perspectives 119 547-552. (doi:10.1289/ehp.1002559)

Calafat AM, Ye X, Wong LY, Reidy JA \& Needham LL 2008 Exposure of the U.S. population to bisphenol A and 4-tertiary-octylphenol: 2003-2004. Environmental Health Perspectives 116 39-44. (doi:10.1289/ehp.10753)

Caldwell HK, Lee HJ, Macbeth AH \& Young WS III 2008 Vasopressin: behavioral roles of an "original" neuropeptide. Progress in Neurobiology 84 1-24. (doi:10.1016/j.pneurobio.2007.10.007) 
Cao J \& Patisaul HB 2011 Sexually dimorphic expression of hypothalamic estrogen receptors $\alpha$ and $\beta$ and kiss 1 in neonatal male and female rats. Journal of Comparative Neurology 519 2954-2977. (doi:10.1002/cne. 22648)

Cao J \& Patisaul HB 2013 Sex specific expression of estrogen receptors $\alpha$ and $\beta$ and kiss1 in the postnatal rat amygdala. Journal of Comparative Neurology 521 465-478. (doi:10.1002/cne.23185)

Cao J, Mickens JA, McCaffrey KA, Leyrer SM \& Patisaul HB 2012 Neonatal bisphenol A exposure alters sexually dimorphic gene expression in the postnatal rat hypothalamus. Neurotoxicology 33 23-36. (doi:10.1016/ j.neuro.2011.11.002)

Cao J, Rebuli ME, Rogers J, Todd KL, Leyrer SM, Ferguson SA \& Patisaul HB 2013 Prenatal bisphenol A exposure alters sex-specific estrogen receptor expression in the neonatal rat hypothalamus and amygdala. Toxicological Sciences 133 157-173. (doi:10.1093/toxsci/kft035)

Chapin RE, Adams J, Boekelheide K, Gray LE Jr, Hayward SW, Lees PS, McIntyre BS, Portier KM, Schnorr TM, Selevan SG et al. 2008 NTPCERHR expert panel report on the reproductive and developmental toxicity of bisphenol A. Birth Defects Research. Part B, Developmental and Reproductive Toxicology 83 157-395. (doi:10.1002/bdrb.20147)

Christoph GR, Leonzio RJ \& Wilcox KS 1986 Stimulation of the lateral habenula inhibits dopamine-containing neurons in the substantia nigra and ventral tegmental area of the rat. Journal of Neuroscience 6 613-619.

Chung WC, Pak TR, Suzuki S, Pouliot WA, Andersen ME \& Handa RJ 2007 Detection and localization of an estrogen receptor $\beta$ splice variant protein (ER $\beta 2)$ in the adult female rat forebrain and midbrain regions. Journal of Comparative Neurology 505 249-267. (doi:10.1002/cne.21490)

Cox KH, Gatewood JD, Howeth C \& Rissman EF 2010 Gestational exposure to bisphenol A and cross-fostering affect behaviors in juvenile mice. Hormones and Behavior 58 754-761. (doi:10.1016/j.yhbeh.2010.07.008)

Degen GH, Janning P, Diel P \& Bolt HM 2002 Estrogenic isoflavones in rodent diets. Toxicology Letters 128 145-157. (doi:10.1016/S03784274(02)00009-7)

De Vries GJ, Buijs RM \& Van Leeuwen FW 1984 Sex differences in vasopressin and other neurotransmitter systems in the brain. Progress in Brain Research 61 185-203.

DeVries GJ, Buijs RM, Van Leeuwen FW, Caffe AR \& Swaab DF 1985 The vasopressinergic innervation of the brain in normal and castrated rats. Journal of Comparative Neurology 233 236-254. (doi:10.1002/cne. 902330206)

Dodds EC \& Lawson W 1936 Synthetic estrogenic agents without the phenanthrene nucleus. Nature 137 996. (doi:10.1038/137996a0)

Doerge DR, Twaddle NC, Woodling KA \& Fisher JW 2010 Pharmacokinetics of bisphenol A in neonatal and adult rhesus monkeys. Toxicology and Applied Pharmacology 248 1-11. (doi:10.1016/j.taap.2010.07.009)

Fan X, Xu H, Warner M \& Gustafsson JA 2010 ER $\beta$ in CNS: new roles in development and function. Progress in Brain Research 181 233-250.

Faulds MH, Zhao C, Dahlman-Wright K \& Gustafsson JA 2012 Regulation of metabolism by estrogen signaling. Journal of Endocrinology 12 3-12. (doi:10.1530/JOE-11-0044)

Gonzalez M, Cabrera-Socorro A, Perez-Garcia CG, Fraser JD, Lopez FJ, Alonso R \& Meyer G 2007 Distribution patterns of estrogen receptor $\alpha$ and $\beta$ in the human cortex and hippocampus during development and adulthood. Journal of Comparative Neurology 503 790-802. (doi:10.1002/cne.21419)

Goodman JE, Witorsch RJ, McConnell EE, Sipes IG, Slayton TM, Yu CJ, Franz AM \& Rhomberg LR 2009 Weight-of-evidence evaluation of reproductive and developmental effects of low doses of bisphenol A. Critical Reviews in Toxicology 39 1-75. (doi:10.1080/ 10408440802157839)

Gore AC 2008 Developmental programming and endocrine disruptor effects on reproductive neuroendocrine systems. Frontiers in Neuroendocrinology 29 358-374. (doi:10.1016/j.yfrne.2008.02.002)

Gould JC, Leonard LS, Maness SC, Wagner BL, Conner K, Zacharewski T, Safe S, McDonnell DP \& Gaido KW 1998 Bisphenol A interacts with the estrogen receptor $\alpha$ in a distinct manner from estradiol. Molecular and Cellular Endocrinology 142 203-214. (doi:10.1016/S03037207(98)00084-7)

Greene G, Gilna P, Waterfield M, Baker A, Hort Y \& Shine J 1986 Sequence and expression of human estrogen receptor complementary DNA. Science 231 1150-1153. (doi:10.1126/science.3753802)
Groff T 2010 Bisphenol A: invisible pollution. Current Opinion in Pediatrics 22 524-529. (doi:10.1097/MOP.0b013e32833b03f8)

Grumbach MM 2002 The neuroendocrinology of human puberty revisited. Hormone Research 2 2-14. (doi:10.1159/000058094)

Handa RJ, Ogawa S, Wang JM \& Herbison AE 2012 Roles for oestrogen receptor $\beta$ in adult brain function. Journal of Neuroendocrinology 24 160-173. (doi:10.1111/j.1365-2826.2011.02206.x)

Harley KG, Gunier RB, Kogut K, Johnson C, Bradman A, Calafat AM \& Eskenazi B 2013 Prenatal and early childhood bisphenol A concentrations and behavior in school-aged children. Environmental Research 126 43-50. (doi:10.1016/j.envres.2013.06.004)

He Z, Paule MG \& Ferguson SA 2012 Low oral doses of bisphenol A increase volume of the sexually dimorphic nucleus of the preoptic area in male, but not female, rats at postnatal day 21. Neurotoxicology and Teratology 34 331-337. (doi:10.1016/j.ntt.2012.03.004)

Hengstler JG, Foth H, Gebel T, Kramer PJ, Lilienblum W, Schweinfurth H, Volkel W, Wollin KM \& Gundert-Remy U 2011 Critical evaluation of key evidence on the human health hazards of exposure to bisphenol A. Critical Reviews in Toxicology 41 263-291. (doi:10.3109/10408444. 2011.558487)

Hikosaka O, Sesack SR, Lecourtier L \& Shepard PD 2008 Habenula: crossroad between the basal ganglia and the limbic system. Journal of Neuroscience 28 11825-11829. (doi:10.1523/JNEUROSCI.3463-08.2008)

Hisasue S, Seney ML, Immerman E \& Forger NG 2010 Control of cell number in the bed nucleus of the stria terminalis of mice: role of testosterone metabolites and estrogen receptor subtypes. Journal of Sexual Medicine 7 1401-1409. (doi:10.1111/j.1743-6109.2009.01669.x)

Howdeshell KL, Hotchkiss AK, Thayer KA, Vandenbergh JG \& vom Saal FS 1999 Exposure to bisphenol A advances puberty. Nature 401 763-764. (doi:10.1038/44517)

Jasarevic E, Sieli PT, Twellman EE, Welsh TH Jr, Schachtman TR, Roberts RM, Geary DC \& Rosenfeld CS 2011 Disruption of adult expression of sexually selected traits by developmental exposure to bisphenol A. PNAS 108 11715-11720. (doi:10.1073/pnas.1107958108)

Jasarevic E, Williams SA, Vandas GM, Ellersieck MR, Liao C, Kannan K, Roberts RM, Geary DC \& Rosenfeld CS 2013 Sex and dose-dependent effects of developmental exposure to bisphenol A on anxiety and spatial learning in deer mice (Peromyscus maniculatus bairdii) offspring. Hormones and Behavior 63 180-189. (doi:10.1016/j.yhbeh.2012.09.009)

Kato J, Hirata S, Koh T, Yamada-Mouri N, Hoshi K \& Okinaga S 1998 The multiple untranslated first exons and promoters system of the oestrogen receptor gene in the brain and peripheral tissues of the rat and monkey and the developing rat cerebral cortex. Journal of Steroid Biochemistry and Molecular Biology 65 281-293. (doi:10.1016/S0960-0760(97)00184-2)

Kelly DA, Varnum MM, Krentzel AA, Krug S \& Forger NG 2013 Differential control of sex differences in estrogen receptor $\alpha$ in the bed nucleus of the stria terminalis and anteroventral periventricular nucleus. Endocrinology 154 3836-3846. (doi:10.1210/en.2013-1239)

Kuhnemann S, Brown TJ, Hochberg RB \& MacLusky NJ 1994 Sex differences in the development of estrogen receptors in the rat brain. Hormones and Behavior 28 483-491. (doi:10.1006/hbeh.1994.1046)

Kuiper GG, Enmark E, Pelto-Huikko M, Nilsson S \& Gustafsson JA 1996 Cloning of a novel estrogen receptor expressed in rat prostate and ovary. PNAS 93 5925-5930. (doi:10.1073/pnas.93.12.5925)

Kuiper GG, Lemmen JG, Carlsson B, Corton JC, Safe SH, van der Saag PT, van der Burg B \& Gustafsson JA 1998 Interaction of estrogenic chemicals and phytoestrogens with estrogen receptor $\beta$. Endocrinology 139 4252-4263. (doi:10.1210/en.139.10.4252)

Kundakovic M, Gudsnuk K, Franks B, Madrid J, Miller RL, Perera FP \& Champagne FA 2013 Sex-specific epigenetic disruption and behavioral changes following low-dose in utero bisphenol A exposure. PNAS 110 9956-9961.

Laflamme N, Nappi RE, Drolet G, Labrie C \& Rivest S 1998 Expression and neuropeptidergic characterization of estrogen receptors (ER $\alpha$ and $E R \beta)$ throughout the rat brain: anatomical evidence of distinct roles of each subtype. Journal of Neurobiology 36 357-378. (doi:10.1002/(SICI)10974695(19980905)36:3 < 357::AID-NEU5>3.0.CO;2-V)

Lakind JS \& Naiman DQ 2010 Daily intake of bisphenol A and potential sources of exposure: 2005-2006 National Health and Nutrition Examination Survey. Journal of Exposure Science and Environmental Epidemiology 21 272-279. 
Lecourtier L \& Kelly PH 2007 A conductor hidden in the orchestra? Role of the habenular complex in monoamine transmission and cognition. Neuroscience and Biobehavioral Reviews 31 658-672. (doi:10.1016/ j.neubiorev.2007.01.004)

Li AA, Baum MJ, McIntosh LJ, Day M, Liu F \& Gray LE Jr 2008 Building a scientific framework for studying hormonal effects on behavior and on the development of the sexually dimorphic nervous system. Neurotoxicology 29 504-519. (doi:10.1016/j.neuro.2008.02.015)

Lonstein JS, Greco B, De Vries GJ, Stern JM \& Blaustein JD 2000 Maternal behavior stimulates c-fos activity within estrogen receptor $\alpha$-containing neurons in lactating rats. Neuroendocrinology 72 91-101. (doi:10.1159/ 000054576)

Losa-Ward SM, Todd KL, McCaffrey KA, Tsutsui K \& Patisaul HB 2012 Disrupted organization of RFamide pathways in the hypothalamus is associated with advanced puberty in female rats neonatally exposed to bisphenol A. Biology of Reproduction 87 28. (doi:10.1095/biolreprod. 112.100826)

Lund TD, Rovis T, Chung WC \& Handa RJ 2005 Novel actions of estrogen receptor- $\beta$ on anxiety-related behaviors. Endocrinology 146 797-807. (doi:10.1210/en.2004-1158)

MacLusky NJ, Chaptal C \& McEwen BS 1979 The development of estrogen receptor systems in the rat brain and pituitary: postnatal development. Brain Research 178 143-160. (doi:10.1016/0006-8993 (79)90094-5)

Madeira MD, Sousa N, Cadete-Leite A, Lieberman AR \& PaulaBarbosa MM 1993 The supraoptic nucleus of the adult rat hypothalamus displays marked sexual dimorphism which is dependent on body weight. Neuroscience 52 497-513. (doi:10.1016/0306-4522(93)90402-2)

McCarthy MM 2008 Estradiol and the developing brain. Physiological Reviews 88 91-124. (doi:10.1152/physrev.00010.2007)

McCarthy MM, Wright CL \& Schwarz JM 2009 New tricks by an old dogma: mechanisms of the Organizational/Activational Hypothesis of steroid-mediated sexual differentiation of brain and behavior. Hormones and Behavior 55 655-665. (doi:10.1016/j.yhbeh.2009.02.012)

Mikkelsen JD \& Simonneaux V 2009 The neuroanatomy of the kisspeptin system in the mammalian brain. Peptides 30 26-33. (doi:10.1016/ j.peptides.2008.09.004)

Mitra SW, Hoskin E, Yudkovitz J, Pear L, Wilkinson HA, Hayashi S, Pfaff DW, Ogawa S, Rohrer SP, Schaeffer JM et al. 2003 Immunolocalization of estrogen receptor $\beta$ in the mouse brain: comparison with estrogen receptor $\alpha$. Endocrinology 144 2055-2067. (doi:10.1210/en.2002-221069)

Murray EK, Hien A, de Vries GJ \& Forger NG 2009 Epigenetic control of sexual differentiation of the bed nucleus of the stria terminalis. Endocrinology 150 4241-4247. (doi:10.1210/en.2009-0458)

Nagao T, Saito Y, Usumi K, Kuwagata M \& Imai K 1999 Reproductive function in rats exposed neonatally to bisphenol $\mathrm{A}$ and estradiol benzoate. Reproductive Toxicology 13 303-311. (doi:10.1016/S08906238(99)00017-9)

Negishi T, Kawasaki K, Suzaki S, Maeda H, Ishii Y, Kyuwa S, Kuroda Y \& Yoshikawa Y 2004 Behavioral alterations in response to fear-provoking stimuli and tranylcypromine induced by perinatal exposure to bisphenol A and nonylphenol in male rats. Environmental Health Perspectives 112 1159-1164. (doi:10.1289/ehp.6961)

Neumann I \& van den Burg E 2011 Oxytocin and vasopressin release and their receptor-mediated intracellular pathways that determine their behavioral effects. Oxytocin, Vasopressin and Related Peptides in the Regulation of Behavior

Newbold RR 2010 Impact of environmental endocrine disrupting chemicals on the development of obesity. Hormones 9 206-217.

Nomura M, McKenna E, Korach K, Pfaff D \& Ogawa S 2002 Estrogen receptor-b regulates transcript levels for oxytocin and arginine vasopressin in the hypothalamic paraventricular nucleus of male mice. Molecular Brain Research 109 84-94. (doi:10.1016/S0169328X(02)00525-9)

NTP 2008 NTP-CERHR Monograph on the Potential Human Reproductive and Developmental Effects of Bisphenol A.: NIH.

Osterlund M, Kuiper GG, Gustafsson JA \& Hurd YL 1998 Differential distribution and regulation of estrogen receptor- $\alpha$ and $-\beta$ mRNA within the female rat brain. Brain Research. Molecular Brain Research 54 175-180. (doi:10.1016/S0169-328X(97)00351-3)
Palanza P, Gioiosa L, vom Saal FS \& Parmigiani S 2008 Effects of developmental exposure to bisphenol A on brain and behavior in mice. Environmental Research 108 150-157. (doi:10.1016/j.envres.2008. 07.023)

Pant J, Ranjan P \& Deshpande SB 2011 Bisphenol A decreases atrial contractility involving NO-dependent G-cyclase signaling pathway. Journal of Applied Toxicology 31 698-702.

Patisaul HB 2005 Phytoestrogen action in the adult and developing brain. Journal of Neuroendocrinology 17 57-64. (doi:10.1111/j.1365-2826. 2005.01268.x)

Patisaul HB \& Bateman HL 2008 Neonatal exposure to endocrine active compounds or an ER $\beta$ agonist increases adult anxiety and aggression in gonadally intact male rats. Hormones and Behavior 53 580-588. (doi:10.1016/j.yhbeh.2008.01.008)

Patisaul HB \& Polston EK 2008 Influence of endocrine active compounds on the developing rodent brain. Brain Research Reviews 57 352-362. (doi:10.1016/j.brainresrev.2007.06.008)

Patisaul HB, Scordalakes EM, Young LJ \& Rissman EF 2003 Oxytocin, but not oxytocin receptor, is regulated by oestrogen receptor $\beta$ in the female mouse hypothalamus. Journal of Neuroendocrinology 15 787-793. (doi:10.1046/j.1365-2826.2003.01061.x)

Patisaul HB, Fortino AE \& Polston EK 2006 Neonatal genistein or bisphenol-A exposure alters sexual differentiation of the AVPV. Neurotoxicology and Teratology 28 111-118. (doi:10.1016/j.ntt.2005.11.004)

Patisaul HB, Fortino AE \& Polston EK 2007 Differential disruption of nuclear volume and neuronal phenotype in the preoptic area by neonatal exposure to genistein and bisphenol-A. Neurotoxicology 28 1-12. (doi:10.1016/j.neuro.2006.10.001)

Patisaul HB, Sullivan AW, Radford ME, Walker DM, Adewale HB, Winnik B, Coughlin JL, Buckley B \& Gore AC 2012 Anxiogenic effects of developmental bisphenol $\mathrm{A}$ exposure are associated with gene expression changes in the juvenile rat amygdala and mitigated by soy. PLOS ONE 7 e43890. (doi:10.1371/journal.pone.0043890)

Paxinos G \& Watson C 2007 The Rat Brain in Stereotaxic Coordinates, London: Academic Press.

Perez SE, Chen EY \& Mufson EJ 2003 Distribution of estrogen receptor $\alpha$ and $\beta$ immunoreactive profiles in the postnatal rat brain. Brain Research. Developmental Brain Research 145 117-139. (doi:10.1016/S01653806(03)00223-2)

Poling MC, Quennell JH, Anderson GM \& Kauffman AS 2013 Kisspeptin neurones do not directly signal to RFRP-3 neurones but RFRP-3 may directly modulate a subset of hypothalamic kisspeptin cells in mice. Journal of Neuroendocrinology 25 876-886. (doi:10.1111/jne. 12084)

Porrini S, Belloni V, Della Seta D, Farabollini F, Giannelli G \& DessiFulgheri F 2005 Early exposure to a low dose of bisphenol A affects sociosexual behavior of juvenile female rats. Brain Research Bulletin 65 261-266. (doi:10.1016/j.brainresbull.2004.11.014)

Reisine TD, Soubrie P, Artaud F \& Glowinski J 1982 Involvement of lateral habenula-dorsal raphe neurons in the differential regulation of striatal and nigral serotonergic transmission cats. Journal of Neuroscience 2 1062-1071.

Report of Joint FAO/WHO Expert Meeting 2011 Toxicological and Health Aspects of Bisphenol A: A final report including report of stakeholder meeting on bisphenol A, 1-5 November 2010, Ottawa, Canada. World Health Organization and Food and Agriculture Organization of the United Nations: Geneva, Switzerland.

Resko JA \& Roselli CE 1997 Prenatal hormones organize sex differences of the neuroendocrine reproductive system: observations on guinea pigs and nonhuman primates. Cellular and Molecular Neurobiology 17 627-648. (doi:10.1023/A:1022534019718)

Rissman EF 2008 Roles of oestrogen receptors $\alpha$ and $\beta$ in behavioural neuroendocrinology: beyond Yin/Yang. Journal of Neuroendocrinology 20 873-879. (doi:10.1111/j.1365-2826.2008.01738.x)

Rochester JR 2013 Bisphenol A and human health: a review of the literature. Reproductive Toxicology 42 132-155. (doi:10.1016/j.reprotox.2013.08.008)

Rosenfeld CS 2012 Effects of maternal diet and exposure to bisphenol A on sexually dimorphic responses in conceptuses and offspring. Reproduction in Domestic Animals 47 (Suppl 4) 23-30. (doi:10.1111/j.14390531.2012.02051.x) 
Rubin BS, Lenkowski JR, Schaeberle CM, Vandenberg LN, Ronsheim PM \& Soto AM 2006 Evidence of altered brain sexual differentiation in mice exposed perinatally to low, environmentally relevant levels of bisphenol A. Endocrinology 147 3681-3691. (doi:10.1210/en.20060189)

vom Saal FS, Akingbemi BT, Belcher SM, Birnbaum LS, Crain DA, Eriksen M, Farabollini F, Guillette LJ Jr, Hauser R, Heindel JJ et al. 2007 Chapel Hill bisphenol A expert panel consensus statement: integration of mechanisms, effects in animals and potential to impact human health at current levels of exposure. Reproductive Toxicology $\mathbf{2 4}$ 131-138. (doi:10.1016/j.reprotox.2007.07.005)

Selevan SG, Kimmel CA \& Mendola P 2000 Identifying critical windows of exposure for children's health. Environmental Health Perspectives 108 (Suppl 3) 451-455.

Shelby MD 2008 NTP-CERHR monograph on the potential human reproductive and developmental effects of bisphenol A. NTP CERHR MON v (vii-ix) 1-64.

Shughrue PJ \& Merchenthaler I 2001 Distribution of estrogen receptor $\beta$ immunoreactivity in the rat central nervous system. Journal of Comparative Neurology 436 64-81. (doi:10.1002/cne.1054)

Shughrue P, Scrimo P, Lane M, Askew R \& Merchenthaler I 1997a The distribution of estrogen receptor- $\beta$ mRNA in forebrain regions of the estrogen receptor- $\alpha$ knockout mouse. Endocrinology 138 5649-5652. (doi:10.1210/en.138.12.5649)

Shughrue PJ, Lane MV \& Merchenthaler I 1997b Comparative distribution of estrogen receptor- $\alpha$ and $-\beta$ mRNA in the rat central nervous system. Journal of Comparative Neurology 388 507-525. (doi:10.1002/ (SICl)1096-9861(19971201)388:4<507::AID-CNE1 > 3.0.CO;2-6)

Simerly RB 2002 Wired for reproduction: organization and development of sexually dimorphic circuits in the mammalian forebrain. Annual Review of Neuroscience 25 507-536. (doi:10.1146/annurev.neuro.25.112701. 142745)

Simerly RB, Chang C, Muramatsu M \& Swanson LW 1990 Distribution of androgen and estrogen receptor mRNA-containing cells in the rat brain: an in situ hybridization study. Journal of Comparative Neurology 294 76-95. (doi:10.1002/cne.902940107)

Sullivan AW, Hamilton P \& Patisaul HB 2011 Neonatal agonism of ER $\beta$ impairs male reproductive behavior and attractiveness. Hormones and Behavior 60 185-194. (doi:10.1016/j.yhbeh.2011.04.006)

Suzuki S \& Handa RJ 2005 Estrogen receptor- $\beta$, but not estrogen receptor- $\alpha$, is expressed in prolactin neurons of the female rat paraventricular and supraoptic nuclei: comparison with other neuropeptides. Journal of Comparative Neurology 484 28-42. (doi:10.1002/cne.20457)

Taylor JA, Welshons WV \& Vom Saal FS 2008 No effect of route of exposure (oral; subcutaneous injection) on plasma bisphenol A throughout 24h after administration in neonatal female mice. Reproductive Toxicology 25 169-176. (doi:10.1016/j.reprotox.2008.01.001)

Thigpen JE, Setchell KD, Padilla-Banks E, Haseman JK, Saunders HE, Caviness GF, Kissling GE, Grant MG \& Forsythe DB 2007 Variations in phytoestrogen content between different mill dates of the same diet produces significant differences in the time of vaginal opening in CD-1 mice and F344 rats but not in CD Sprague-Dawley rats. Environmental Health Perspectives 115 1717-1726. (doi:10.1289/ehp. 10165)
Thigpen JE, Setchell KD, Kissling GE, Locklear J, Caviness GF, Whiteside T, Belcher SM, Brown NM, Collins BJ, Lih FB et al. 2013 The estrogenic content of rodent diets, bedding, cages, water bottles and its effect on bisphenol A studies. Journal of the American Association for Laboratory Animal Science 52 130-141.

Vandenberg LN, Hauser R, Marcus M, Olea N \& Welshons WV 2007 Human exposure to bisphenol A (BPA). Reproductive Toxicology 24 139-177. (doi:10.1016/j.reprotox.2007.07.010)

Vandenberg LN, Maffini MV, Sonnenschein C, Rubin BS \& Soto AM 2009 Bisphenol-A and the great divide: a review of controversies in the field of endocrine disruption. Endocrine Reviews 30 75-95. (doi:10.1210/er. 2008-0021)

Vida B, Hrabovszky E, Kalamatianos T, Coen CW, Liposits Z \& Kallo I 2008 Oestrogen receptor $\alpha$ and $\beta$ immunoreactive cells in the suprachiasmatic nucleus of mice: distribution, sex differences and regulation by gonadal hormones. Journal of Neuroendocrinology 20 1270-1277. (doi:10.1111/ j.1365-2826.2008.01787.x)

Walker DM, Juenger TE \& Gore AC 2009 Developmental profiles of neuroendocrine gene expression in the preoptic area of male rats. Endocrinology 150 2308-2316. (doi:10.1210/en.2008-1396)

Wallen K 2005 Hormonal influences on sexually differentiated behavior in nonhuman primates. Frontiers in Neuroendocrinology 26 7-26. (doi:10. 1016/j.yfrne.2005.02.001)

Wilson ME \& Westberry JM 2009 Regulation of oestrogen receptor gene expression: new insights and novel mechanisms. Journal of Neuroendocrinology 21 238-242. (doi:10.1111/j.1365-2826.2009.01830.x)

Wolstenholme JT, Rissman EF \& Connelly JJ 2011 The role of bisphenol A in shaping the brain, epigenome and behavior. Hormones and Behavior 59 296-305. (doi:10.1016/j.yhbeh.2010.10.001)

Wolstenholme JT, Edwards M, Shetty SR, Gatewood JD, Taylor JA, Rissman EF \& Connelly JJ 2012 Gestational exposure to bisphenol A produces transgenerational changes in behaviors and gene expression. Endocrinology 153 3828-3838. (doi:10.1210/en.2012-1195)

Yokosuka M, Okamura H \& Hayashi S 1997 Postnatal development and sex difference in neurons containing estrogen receptor- $\alpha$ immunoreactivity in the preoptic brain, the diencephalon, the amygdala in the rat. Journal of Comparative Neurology 389 81-93. (doi:10.1002/(SICl)10969861(19971208)389:1 < 81::AID-CNE6 > 3.0.CO;2-A)

Young WS III \& Gainer H 2003 Transgenesis and the study of expression, cellular targeting and function of oxytocin, vasopressin and their receptors. Neuroendocrinology 78 185-203. (doi:10.1159/000073702)

Zhang JQ, Cai WQ, Zhou DS \& Su BY 2002 Distribution and differences of estrogen receptor $\beta$ immunoreactivity in the brain of adult male and female rats. Brain Research 935 73-80. (doi:10.1016/S00068993(02)02460-5)

Received 3 October 2013

First decision 14 November 2013

Revised manuscript received 23 November 2013

Accepted 18 December 2013 